\title{
Comparative transcriptomic analysis of Rickettsia conorii during in vitro infection of human and tick host cells
}

Hema P. Narra ${ }^{1 *}$, Abha Sahni ${ }^{1}$, Jessica Alsing ${ }^{1}$, Casey L. C. Schroeder ${ }^{1}$, George Golovko², Anna M. Nia ${ }^{3}$, Yuriy Fofanov ${ }^{2}$, Kamil Khanipov ${ }^{2}$ and Sanjeev K. Sahni ${ }^{*}$

\begin{abstract}
Background: Pathogenic Rickettsia species belonging to the spotted fever group are arthropod-borne, obligate intracellular bacteria which exhibit preferential tropism for host microvascular endothelium in the mammalian hosts, resulting in disease manifestations attributed primarily to endothelial damage or dysfunction. Although rickettsiae are known to undergo evolution through genomic reduction, the mechanisms by which these pathogens regulate their transcriptome to ensure survival in tick vectors and maintenance by transovarial/transstadial transmission, in contrast to their ability to cause debilitating infections in human hosts remain unknown. In this study, we compare the expression profiles of rickettsial sRNAome/transcriptome and determine the transcriptional start sites (TSSs) of $R$. conorii transcripts during in vitro infection of human and tick host cells.
\end{abstract}

Results: We performed deep sequencing on total RNA from Amblyomma americanum AAE2 cells and human microvascular endothelial cells (HMECs) infected with $R$. conorii. Strand-specific RNA sequencing of $R$. conorii transcripts revealed the expression 32 small RNAs ( $\left.R c_{-} s R^{\prime} s\right)$, which were preferentially expressed above the limit of detection during tick cell infection, and confirmed the expression of Rc_sR61, sR71, and sR74 by quantitative RT-PCR. Intriguingly, a total of 305 and 132 R. conorii coding genes were differentially upregulated (> 2-fold) in AAE2 cells and HMECs, respectively. Further, enrichment for primary transcripts by treatment with Terminator 5'-Phosphate-dependent Exonuclease resulted in the identification of 3903 and 2555 transcription start sites (TSSs), including 214 and 181 primary TSSs in R. conorii during the infection to tick and human host cells, respectively. Seventy-five coding genes exhibited different TSSs depending on the host environment. Finally, we also observed differential expression of $6 \mathrm{~S}$ RNA during host-pathogen and vector-pathogen interactions in vitro, implicating an important role for this noncoding RNA in the regulation of rickettsial transcriptome depending on the supportive host niche.

Conclusions: In sum, the findings of this study authenticate the presence of novel $R c_{-} s R$ 's in $R$. conorii, reveal the first evidence for differential expression of coding transcripts and utilization of alternate transcriptional start sites depending on the host niche, and implicate a role for $6 \mathrm{~S}$ RNA in the regulation of coding transcriptome during tripartite hostpathogen-vector interactions.

Keywords: Rickettsia, Endothelial cells, Tick vector, Small RNAs, 6S RNA, Transcriptome, Transcription start sites, and Terminator 5'-phosphate-dependent exonuclease (TEX)

\footnotetext{
*Correspondence: hpnarra@utmb.edu; sksahni@utmb.edu

'Department of Pathology, University of Texas Medical Branch, Galveston, TX

77555, USA

Full list of author information is available at the end of the article
}

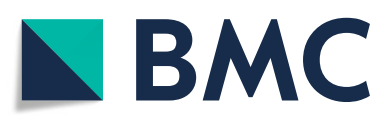

(c) The Author(s). 2020 Open Access This article is licensed under a Creative Commons Attribution 4.0 International License, which permits use, sharing, adaptation, distribution and reproduction in any medium or format, as long as you give appropriate credit to the original author(s) and the source, provide a link to the Creative Commons licence, and indicate if changes were made. The images or other third party material in this article are included in the article's Creative Commons licence, unless indicated otherwise in a credit line to the material. If material is not included in the article's Creative Commons licence and your intended use is not permitted by statutory regulation or exceeds the permitted use, you will need to obtain permission directly from the copyright holder. To view a copy of this licence, visit http://creativecommons.org/licenses/by/4.0/. The Creative Commons Public Domain Dedication waiver (http://creativecommons.org/publicdomain/zero/1.0/) applies to the data made available in this article, unless otherwise stated in a credit line to the data. 


\section{Background}

Human pathogens in the family Rickettsiaceae include Gram-negative bacteria capable of establishing an intracellular habitat as obligate intracellular parasites to derive energy and nutrients from the host cytosol for their growth, replication, and dissemination. Rickettsial infections associated with significant morbidity and mortality constitute a significant health scourge across the globe $[1,2]$. Mediterranean spotted fever due to Rickettsia conorii is an acute febrile zoonotic disease with flu-like initial symptoms and typically associated with eschars at the bite sites of tick vectors [3]. Transovarial and transstadial transmission are considered to be the major driving forces for $R$. conorii maintenance and persistence in its natural arthropod vectors [3]. In its mammalian hosts, including humans, $R$. conorii exhibits tropism for human microvascular endothelium lining the small or medium-sized blood vessels leading to vascular inflammation and dysfunction manifesting as increased vascular permeability, fluid imbalance, and edema of vital organ systems [4].

Transcriptional and epigenetic regulation of the transcriptome is presumed to play a vital role in rickettsial homeostasis during their transition and establishment in homoeothermic mammalian hosts vis-à-vis tick (poikilothermic) vectors. Limited transcriptional changes occurring due to a shift in growth temperature $\left(37^{\circ} \mathrm{C}\right.$ vs $25^{\circ} \mathrm{C}$ ), iron limitation, or infection of different host cell species in vitro have been reported for $R$. rickettsii. Microarray based transcriptomic analysis of the typhus group pathogen $R$. typhi grown at different temperatures has shown up- and down-regulation of a total of 70 and 60 genes upon temperature shift from $37^{\circ} \mathrm{C}$ to $25^{\circ} \mathrm{C}$, respectively $[5,6]$. Interestingly, 56 genes are differentially regulated in $R$. rickettsii in response to a cold shock $\left(4^{\circ} \mathrm{C}\right)$, indicating the intrinsic ability of this pathogen to respond to changes in environmental cues, in vitro [5]. On the other hand, about $13 \%$ of $R$. rickettsii genes are differentially modulated by temperature upshift from $25^{\circ} \mathrm{C}$ to $35^{\circ} \mathrm{C}$, and acquisition of blood meal by tick vectors. Notably, while genes involved in DNA replication, recombination and repair, vesicular transport and secretion, and energy production and conversion display induced expression, a majority of genes involved in translation, ribosomal structure, and biogenesis pathways are downregulated during the process of tick feeding [7]. In addition, rickettsial gene expression is also influenced by tick gender and organ of colonization. Nearly 67 and $80 \%$ of the 85 rickettsial genes tested have been reported to be differentially expressed in salivary glands and midguts, respectively. While genes encoding type IV secretion system were exclusively induced in females during rickettsial infection, co-chaperone $\mathrm{HscB}$, and thioredoxin peroxidase 1 were expressed only in male ticks [8]. Together, these findings signify the importance of blood feeding, colonizing organ, and tick gender on rickettsial gene expression as the potential basis for altered virulence during natural transmission from the transmitting vector to the mammalian hosts.

The effect of host environment (human vis-à-vis arthropod) on bacterial transcriptional landscape has been documented for several other vector-borne pathogens, including Borrelia, Anaplasma, and Ehrlichia [9-11]. Comparative transcriptomic analysis of A. phagocytophilum grown in human (HL-60) and tick (ISE6) cells results in differential expression of $41.5 \%$ of the genes, of which 117 exhibit greater than two-fold change [12]. In Borrelia, OspA is highly expressed during its colonization in ticks, and $\mathrm{OspC}$ is upregulated during tick feeding and transmission, leading to the hypothesis that warm host blood and changes in the temperature during feeding act as a trigger for the modulation of gene expression [13, 14]. Further, Borrelia OspB mutants exhibit impaired ability to adhere to gut tissues and survive in tick vectors despite their ability to infect and persist in mice [15]. In contrast, other borrelial genes, namely OspE/F, Arp, P47, and P66, are highly expressed in an infected mammalian host and implicated in host defense and colonization of the vertebrate host $[16,17]$. Collectively, these studies suggest an important role for the host environment on the changes in the regulation of transcriptional expression in bacterial pathogens.

Riboregulation of bacterial coding transcriptome by small non-coding RNAs (sRNAs) is being increasingly recognized within the past few years. In this context, several bacterial sRNAs have now been identified to be differentially expressed depending on the host niche, stress conditions, as well as specific growth requirements, and important roles for these sRNAs in cellular networks and transcriptional regulatory circuits have been documented $[18,19]$. Nearly $45 \%$ of Pseudomonas putida sRNAs have been projected to be differentially regulated during osmotic and oxidative stress conditions [20]. Interestingly, PinT, a PhoP activated sRNA of Salmonella, not only regulates bacterial coding transcriptome required for the invasion and internalization during in vivo infection, but is also involved in the regulation of several other genes essential for the activation of host cell JAK-STAT signaling pathway and expression of long non-coding RNAs, thus exemplifying important contributory roles for a bacterial small RNA in the regulation of eukaryotic host responses [21]. In recent years, we have applied a combinatorial strategy involving computational and deep sequencing approaches to identify, validate, and characterize bona fide sRNAs and their target genes in Rickettsia species belonging to both spotted fever and typhus groups [22-24]. Additionally, RNA sequencing of $R$. prowazekii transcriptome during in vitro infection of human versus tick cells as the host revealed 
differential expression of coding transcripts and sRNAs in a host-niche specific manner [25].

In the present study, we report the comparative analysis of $R$. conorii transcriptome during the infection of cultured human endothelial cells and tick cells as the host. Deep sequencing of bacterial coding and non-coding transcripts revealed differential expression of several genes dependent on the supportive host cell. Approximately $19 \%$ of $R$. conorii genes were differentially and highly expressed during tick cell infection, whereas only $8 \%$ of the genes were highly expressed in host HMECs. Overall, a greater number of genes were expressed above the limit of detection during tick cell infection when compared to HMECs. We have also identified $32 R c \_s R s$ to be abundantly expressed during tick AAE2 cell infection when compared to HMECs and validated their expression during in vitro infection of both HMECs and tick cells. We have further determined the differential expression of $R$. conorii 6S RNA depending on the host niche, allowing us to implicate a role for this bacterial sRNA in the regulation of coding transcriptome during host-pathogen and vector-pathogen interactions.

\section{Results \\ Coding transcriptome of $R$. conorii during in vitro infection of human ECs versus tick cells}

To decode the transcriptional landscape of $R$. conorii during in vitro infection of human and tick cells as the host, we performed deep sequencing on enriched bacterial RNA isolated from HMECs and AAE2 cells infected with $R$. conorii for $24 \mathrm{~h}$. The rationale for selecting this time point was to allow for adhesion and internalization known to occur almost instantaneously followed by two cycles of replication by intracellular rickettsiae based on their replication time of 9 to $11 \mathrm{~h}$ [4]. To ensure valid comparison between host cells under study, we determined the levels of internalized $R$. conorii in human and tick cells and observed similar levels of infection (Additional file 1). We sequenced an average of about 73 million reads from both HMECs as well as AAE2 cells infected with $R$. conorii, of which 26.7 and $18.5 \%$ mapped to $R$. conorii genome, respectively. From a total of 1579 annotated coding genes, only 21 genes, including 19 designated as encoding for hypothetical proteins and annotated only by PATRIC, were expressed below the limit of detection in both cell types. The remaining two genes annotated as $R C 0419$ and RCO453 are present in $R$. conorii in the PATRIC as well as NCBI databases for sequenced rickettsial genomes (Additional file 2). In addition, 7 relatively small genes ranging between 102 and $144 \mathrm{bp}$ and annotated only by PATRIC were expressed in HMECs, but not in AAE2 cells. Conspicuously, a much larger repertoire of 125 genes, of which 64 have been annotated by both PATRIC and NCBI, were expressed only in tick cells. These included genes coding for integration host factor beta subunit (RC0757), competence protein $\mathrm{F}$ homolog (peg.961), Bcr/ CflA family multidrug resistance transporter (peg.1053), toxin-antitoxin system ( $R C 0914$ and RC1143), and plasmid maintenance system antidote protein (peg.521), in addition to a considerable number (61) of transcripts coding for hypothetical proteins with unknown function (Additional file 2).

Interestingly, $\mathrm{N}$-acetylmuramoyl-L-alanine amidase (RC0497) was determined to be the most abundantly expressed transcript during the infection of both tick and human host cells (Tables 1 and 2). The outer membrane protein B $(\operatorname{romp} B)$, heat shock protein 60 family chaperones (groEL and groES), cold shock protein $(\operatorname{csp} A)$, antitoxins of relE (RC1223) and vapC (vapB), tol-pal system peptidoglycan-associated protein ( $\mathrm{pal}$ ), CarD like transcription factor (carD), translation elongation factor $\mathrm{Tu}(t u f)$, and rickA involved in actin based motility were among the top $20 R$. conorii genes highly expressed during infection of tick and host cells (Tables 1 and 2). To further identify $R$. conorii genes differentially expressed during human endothelium versus tick cell infection, we conducted a comparative analysis of the normalized gene expression datasets. The findings revealed that 305 genes were highly expressed $\left(\log _{2}\right.$ fold change $\left.\geq 2.0\right)$ in tick AAE2 cells, whereas only 132 genes displayed differential upregulation in human ECs (Additional file 2). A majority ( 90\%) of top 20 differentially and highly expressed genes in tick AAE2 cells and HMECs encoded hypothetical proteins with putative functions (Tables 3 and 4). BLASTp analysis revealed that while genes predicted to encode for tetratricopeptide repeat proteins, acid phosphatase, metalloprotease, and transcriptional regulator activities were distinctly upregulated in tick cells, those likely involved in transport, toxin-antitoxin system, nucleotide synthesis, and membrane proteins were abundantly expressed in HMECs (Tables 3 and 4). R. conorii RC0446 and RC0511, presumed to function respectively as an M61 glycyl aminopeptidase and AbrB family transcriptional regulator, and peg.0696 with a hypothetical function, were the top three differentially and highly expressed genes in tick cells $\left(\log _{2}\right.$ fold change $\left.>5.0\right)$. On the other hand, $\mathrm{RC} 0257$, coding for a putative autotransporter outer membrane betabarrel domain containing protein was the only gene upregulated at a threshold of $>5.0 \log _{2}$ fold during $R$. conorii infection of HMECs (Tables 3 and 4; Additional file 2).

As a follow up to the global profiling above, we next focused on the expression of genes involved in lipopolysaccharide biosynthesis, type IV secretion system and secreted effectors, as well as those coding for the proteins containing ankyrin repeats. Of the 19 analyzed genes involved in LPS biosynthesis and transport, only RC0486 and $\mathrm{RC} 1055$ encoding for Lipid A core-O-antigen ligase and phosphorylcholine transferase were slightly 
Table 1 List of top 20 R. conorii genes highly expressed during the infection of tick vector cells, in vitro

\begin{tabular}{|c|c|c|c|c|}
\hline Gene ID & Gene Name & Product & Gene Length & TPM \\
\hline RC0497 & & $\mathrm{N}$-acetylmuramoyl-L-alanine amidase & 804 & 43,824 \\
\hline RC0909 & rickA & Involved in actin based motility & 1554 & 12,329 \\
\hline RC1223 & & Antitoxin to RelE-like translational repressor toxin & 429 & 8472 \\
\hline RC0813 & & Hypothetical protein & 237 & 8391 \\
\hline RC1085 & rompB & Outer membrane protein $B$ & 4968 & 8203 \\
\hline RC1008 & tuf & Translation elongation factor Tu & 1185 & 7505 \\
\hline RC0968 & groEL & Heat shock protein 60 family chaperone GroEL & 1647 & 7137 \\
\hline RC1021 & $\operatorname{csp} A$ & Cold shock protein of CSP family & 213 & 6689 \\
\hline RC0207 & & Conserved hypothetical protein & 954 & 6560 \\
\hline RC1200 & pal & Tol-Pal system peptidoglycan-associated lipoprotein & 468 & 6137 \\
\hline RC0876 & & Uncharacterized protein RT0563 & 210 & 6002 \\
\hline RC0969 & groEs & Heat shock protein 60 family co-chaperone GroES & 288 & 5353 \\
\hline RC0858 & & Cell division protein MraZ & 450 & 5294 \\
\hline RC1071 & & type II toxin-antitoxin system HicB family antitoxin & 345 & 5105 \\
\hline RC0030 & carD & CarD-like transcriptional regulator & 522 & 5033 \\
\hline RC0380 & $\operatorname{vap} B$ & VapB protein (antitoxin to VapC) & 288 & 4949 \\
\hline RC1020 & rhIE & DEAD-box ATP-dependent RNA helicase CshA & 1245 & 4601 \\
\hline RC0060 & & Hypothetical protein & 492 & 4285 \\
\hline peg.1340 & & Hypothetical protein & 129 & 4197 \\
\hline RC0649 & & Hypothetical protein & 183 & 4054 \\
\hline
\end{tabular}

TPM Transcripts per million

Table 2 List of top 20 R. conorii genes highly expressed during the infection of human host cells, in vitro

\begin{tabular}{|c|c|c|c|c|}
\hline Gene ID & Gene Name & Product & Gene Length & TPM \\
\hline RC0497 & & $\mathrm{N}$-acetylmuramoyl-L-alanine amidase & 804 & 28,819 \\
\hline RC0949 & $\operatorname{rps} U$ & SSU ribosomal protein S21p & 201 & 21,374 \\
\hline RC1021 & $\operatorname{csp} A$ & Cold shock protein of CSP family & 213 & 15,638 \\
\hline RC0909 & rickA & Involved in actin based motility & 1554 & 14,586 \\
\hline RC0813 & & Hypothetical protein & 237 & 14,037 \\
\hline RC0277 & & Hypothetical protein & 216 & 11,593 \\
\hline $\mathrm{RC} 1223$ & & Antitoxin to RelE-like translational repressor toxin & 429 & 9342 \\
\hline RC0207 & & Hypothetical protein & 954 & 8478 \\
\hline RC0968 & groEL & Heat shock protein 60 family chaperone GroEL & 1647 & 8364 \\
\hline RC1008 & tuf & Translation elongation factor Tu & 1185 & 8315 \\
\hline RC1085 & rompB & Outer membrane protein $B$ & 4968 & 8300 \\
\hline RC1200 & pal & Tol-Pal system peptidoglycan-associated lipoprotein & 468 & 7930 \\
\hline RC0876 & & Uncharacterized protein RT0563 & 210 & 7902 \\
\hline RC0152 & $r p / s$ & LSU ribosomal protein L19p & 417 & 7473 \\
\hline RC1362 & & Hypothetical protein & 165 & 6888 \\
\hline RC0060 & & Hypothetical protein & 492 & 6643 \\
\hline RC0315 & rp/M & LSU ribosomal protein L13p (L13Ae) & 468 & 6487 \\
\hline RC0668 & & Hypothetical protein & 378 & 6398 \\
\hline RC0030 & & CarD-like transcriptional regulator & 522 & 6376 \\
\hline RC0380 & $\operatorname{vap} B$ & VapB protein (antitoxin to VapC) & 288 & 6320 \\
\hline
\end{tabular}


Table 3 List of top 20 R. conorii genes differentially expressed during the infection of tick vector AAE2 cells, in vitro

\begin{tabular}{|c|c|c|c|c|c|c|c|c|c|}
\hline \multirow[t]{2}{*}{ Gene ID } & \multirow[t]{2}{*}{ Product } & \multirow{2}{*}{$\begin{array}{l}\text { Gene } \\
\text { Length } \\
\text { (bp) }\end{array}$} & \multicolumn{2}{|l|}{ TPM } & \multirow{2}{*}{$\begin{array}{l}\log _{2} \\
\text { Change }\end{array}$} & \multicolumn{4}{|l|}{ Homologous to } \\
\hline & & & $\mathrm{AAE} 2+R C$ & $\mathrm{HMEC}+R c$ & & Product & Organism & $\begin{array}{l}\mathrm{E}- \\
\text { value }\end{array}$ & $\begin{array}{l}\text { Identity } \\
(\%)\end{array}$ \\
\hline RC0446 & Hypothetical protein & 291 & 377 & 8 & 5.64 & $\begin{array}{l}\text { M61 glycyl } \\
\text { aminopeptidase family } \\
\text { protein }\end{array}$ & R. rhipicephali & $6 e-52$ & $92 \%$ \\
\hline RC0511 & Hypothetical protein & 249 & 367 & 9 & 5.38 & $\begin{array}{l}\text { Transcriptional regulator, } \\
\text { AbrB family }\end{array}$ & R. massiliae & $1 e-50$ & $100 \%$ \\
\hline peg.0696 & Hypothetical protein & 132 & 539 & 17 & 5.02 & - & - & - & - \\
\hline peg.1306 & Hypothetical protein & 114 & 415 & 19 & 4.43 & $\begin{array}{l}\text { Acetyl-CoA } \\
\text { acetyltransferase }\end{array}$ & Thermoplasmata & $1 e-05$ & $48 \%$ \\
\hline RC0418 & Hypothetical protein & 672 & 119 & 7 & 4.18 & $\begin{array}{l}\text { Tetratricopeptide repeat } \\
\text { family protein }\end{array}$ & R. hoogstraalii & $\begin{array}{l}2 \mathrm{e}- \\
121\end{array}$ & $81 \%$ \\
\hline $\mathrm{RC} 1248$ & Hypothetical protein & 153 & 234 & 14 & 4.03 & $\begin{array}{l}\text { HEPN domain-containing } \\
\text { protein }\end{array}$ & R. asembonensis & $2 e-07$ & $92 \%$ \\
\hline peg.0362 & Hypothetical protein & 117 & 297 & 19 & 3.98 & - & - & - & - \\
\hline peg.0481 & Hypothetical protein & 198 & 338 & 22 & 3.93 & $\begin{array}{l}\text { CPBP family } \\
\text { intramembrane } \\
\text { metalloprotease }\end{array}$ & R. gravesii & $4 e-35$ & $93 \%$ \\
\hline RC0253 & Hypothetical protein & 270 & 343 & 24 & 3.81 & - & - & - & - \\
\hline RC0979 & $\begin{array}{l}\text { DnaA regulatory inactivator } \\
\text { Hda (Homologous to } \\
\text { DnaA) }\end{array}$ & 669 & 138 & 10 & 3.81 & & & & \\
\hline RC0034 & $\begin{array}{l}\text { Dihydrofolate reductase } \\
\text { (FolA) }\end{array}$ & 495 & 62 & 4 & 3.8 & & & & \\
\hline RC0570 & $\begin{array}{l}\text { RND efflux system, } \\
\text { membrane fusion protein }\end{array}$ & 297 & 282 & 22 & 3.67 & & & & \\
\hline RC1250 & Hypothetical protein & 246 & 417 & 36 & 3.54 & $\begin{array}{l}\text { Palindromic element RPE1 } \\
\text { domain-containing } \\
\text { protein }\end{array}$ & SFG rickettsiae & $7 e-51$ & $100 \%$ \\
\hline RC0640 & Hypothetical protein & 420 & 304 & 26 & 3.54 & $\begin{array}{l}\text { Fimbrial biogenesis outer } \\
\text { membrane usher protein }\end{array}$ & R. gravesii & $2 e-65$ & $96 \%$ \\
\hline RC0957 & Hypothetical protein & 201 & 245 & 22 & 3.49 & $\begin{array}{l}\text { Tetratricopeptide repeat } \\
\text { protein }\end{array}$ & SFG rickettsiae & $1 e-17$ & $97 \%$ \\
\hline RC0471 & Hypothetical protein & 249 & 193 & 18 & 3.45 & $\begin{array}{l}\text { Tetratricopeptide repeat } \\
\text { protein }\end{array}$ & R. hoogstraalii & $7 e-46$ & $95 \%$ \\
\hline RC0513 & Hypothetical protein & 186 & 388 & 35 & 3.45 & - & - & - & - \\
\hline peg.0400 & Hypothetical protein & 144 & 332 & 31 & 3.44 & $\begin{array}{l}\text { Acid phosphatase family } \\
\text { protein }\end{array}$ & $\begin{array}{l}R . \\
\text { amblyommatis }\end{array}$ & $5 e-26$ & $94 \%$ \\
\hline RC1293 & Hypothetical protein & 195 & 363 & 34 & 3.43 & - & - & - & - \\
\hline peg.0013 & Hypothetical protein & 135 & 172 & 16 & 3.4 & Toxin & R. tamurae & 0.086 & $90 \%$ \\
\hline
\end{tabular}

Only R. conorii proteins annotated as 'hypothetical protein' were searched by BLASTp to identify the homologous protein in other bacteria

"-"indicates no known homolog was identified in a BLASTp search

TPM Transcripts per million

Log 2 Change $=\log _{2}($ TPM of AAE2 $+R c /$ TPM of HMEC $+R C)$

upregulated (2.21 and 2.34 fold, respectively) during tick cell infection as compared to HMECs. The remaining 17 genes exhibited similar levels (fold changes of $< \pm 2$ ) of transcript abundance in both cell types at $24 \mathrm{~h}$ postinfection (Additional file 3A). With the notable exception of virB7 (RC0386) expressed at detectable levels only during the infection of tick cells, all other component genes of type IV secretion system were expressed in both tick and human cells. RC0144 (virB6), RC0385
(virB8), and RC0388 (virB9) were slightly upregulated at 2.5-, 2.9- and 2.6-fold, respectively, during tick cell infection when compared to HMECs (Additional file 3B). Further, similar levels of transcript abundance were evident for all rickettsial effectors barring VapC, known to encode an antitoxin to VapB toxin. VapC was highly upregulated in HMECs as the host $(\mathrm{TPM}=5969)$, as compared to tick cells $(\mathrm{TPM}=2855)$. Amongst all known rickettsial effectors, rick $A$ had the highest expression in 
Table 4 List of top 20 R. conorii genes differentially expressed during the infection of human microvascular endothelial cells, in vitro

\begin{tabular}{|c|c|c|c|c|c|c|c|c|c|}
\hline \multirow[t]{2}{*}{ Gene ID } & \multirow[t]{2}{*}{ Product } & \multirow{2}{*}{$\begin{array}{l}\text { Gene } \\
\text { Length } \\
\text { (bp) }\end{array}$} & \multicolumn{2}{|l|}{ TPM } & \multirow{2}{*}{$\begin{array}{l}\text { Log2 } \\
\text { Change }\end{array}$} & \multicolumn{4}{|l|}{ Homologous to } \\
\hline & & & $\begin{array}{l}\text { AAE2 + } \\
\text { Rc }\end{array}$ & $\begin{array}{l}\mathrm{HMEC}+ \\
\mathrm{Rc}\end{array}$ & & Product & Organism & $\begin{array}{l}\mathrm{E}- \\
\text { value }\end{array}$ & $\begin{array}{l}\text { Identity } \\
\text { (\%) }\end{array}$ \\
\hline RC0257 & Hypothetical protein & 135 & 8 & 743 & 6.52 & $\begin{array}{l}\text { Autotransporter outer membrane } \\
\text { beta-barrel domain-containing } \\
\text { protein }\end{array}$ & $\begin{array}{l}\text { Citrobacter } \\
\text { farmeri }\end{array}$ & $7 e-04$ & $15 \%$ \\
\hline peg.1116 & Hypothetical protein & 114 & 10 & 263 & 4.78 & $\begin{array}{l}\text { Sugar (and other) transporter } \\
\text { family protein }\end{array}$ & R. hoogstraalii & $2 e-14$ & 92 \\
\hline peg.0736 & Hypothetical protein & 186 & 6 & 130 & 4.47 & $\begin{array}{l}\text { Spore Coat Protein } U \text { domain } \\
\text { protein }\end{array}$ & R. hoogstraalii & $2 e-21$ & 89 \\
\hline peg.0341 & Hypothetical protein & 129 & 25 & 522 & 4.36 & $\begin{array}{l}\text { ATP-binding cassette domain- } \\
\text { containing protein }\end{array}$ & R. fournieri & $3 e-13$ & 92 \\
\hline RC0682 & $\begin{array}{l}\text { LSU ribosomal protein } \\
\text { L36p, zinc-independent } \\
\text { (RpmJ) }\end{array}$ & 126 & 26 & 494 & 4.25 & & & & \\
\hline RC0395 & Hypothetical protein & 297 & 11 & 187 & 4.09 & - & - & - & - \\
\hline RC1180 & Hypothetical protein & 138 & 24 & 302 & 3.67 & MFS transporter & $\begin{array}{l}\text { Chrysiogenales } \\
\text { bacterium }\end{array}$ & $7 e-06$ & 39 \\
\hline RC1181 & Hypothetical protein & 267 & 45 & 526 & 3.55 & Putative MFS transporter & $\begin{array}{l}\text { Aeromonas } \\
\text { salmonicida }\end{array}$ & $6 e-22$ & 34 \\
\hline peg.0129 & Hypothetical protein & 120 & 27 & 311 & 3.51 & ATP synthase A chain & R. slovaca & 0.009 & 100 \\
\hline peg.1274 & Hypothetical protein & 114 & 57 & 546 & 3.25 & - & - & - & - \\
\hline RC0196 & Hypothetical protein & 174 & 13 & 114 & 3.18 & $\begin{array}{l}\text { Nucleoside triphosphate } \\
\text { pyrophosphohydrolase }\end{array}$ & M. smegmatis & $5 e-17$ & 45 \\
\hline RC1177 & Hypothetical protein & 240 & 32 & 265 & 3.06 & MFS transporter & R. felis & $5 e-30$ & 84 \\
\hline $\mathrm{RC} 1123$ & Hypothetical protein & 156 & 7 & 56 & 3.01 & Myotubularin-related protein 10-B & Cephus cinctus & $4 \mathrm{e}-13$ & 27 \\
\hline peg.0810 & Hypothetical protein & 114 & 29 & 218 & 2.93 & $\begin{array}{l}\text { Type II toxin-antitoxin system } \\
\text { RelB/DinJ family antitoxin }\end{array}$ & Psychrobacter & $4 e-10$ & 30 \\
\hline peg.1527 & Hypothetical protein & 129 & 42 & 307 & 2.86 & - & - & - & - \\
\hline RC0824 & Hypothetical protein & 282 & 71 & 503 & 2.83 & BrnT family toxin & Limnohabitans & $2 e-19$ & 52 \\
\hline RC0149 & Acetate kinase (EC 2.7.2.1) & 252 & 9 & 61 & 2.82 & & & & \\
\hline RC0530 & Rickettsial conserved & 207 & 68 & 477 & 2.8 & $\begin{array}{l}\text { Holliday junction ATP-dependent } \\
\text { DNA helicase RuvA }\end{array}$ & R. fournieri & $1 e-13$ & 97 \\
\hline RC0364 & Hypothetical protein & 186 & 176 & 1109 & 2.66 & $\begin{array}{l}\text { Palindromic element RPE1 } \\
\text { domain-containing protein }\end{array}$ & R. hoogstraalii & $1 e-20$ & 80 \\
\hline RC0033 & PqqC-like protein & 303 & 75 & 471 & 2.64 & $\begin{array}{l}\text { Pyrroloquinoline quinone } \\
\text { biosynthesis protein PqqC }\end{array}$ & R. japonica & $6 e-34$ & 97 \\
\hline
\end{tabular}

Only R. conorii proteins annotated as 'hypothetical protein' were searched by BLASTp to identify the homologous protein in other bacteria

"-"indicates no known homolog was identified in a BLASTp search

TPM: Transcripts per million

Log2 Change $=\log _{2}($ TPM of HMEC $+R c /$ TPM of AAE2 $+R c)$

both cell types. Intriguingly, with the exception of $R C 0700$ which was slightly upregulated (> 2-fold) in infected HMECs, all other proteins containing ankyrin repeats showed higher transcript abundance in tick AAE2 cells (Additional file 3C). RC0502 and RC0877 were highly expressed in tick cells as indicated by an increase of 9.9- and 7.7-fold when compared to HMECs (Additional file 3C). Collectively, comparative transcriptional profile of $R$. conorii during the infection of human ECs and tick cells not only confirmed the expression of multiple genes encoding hypothetical functions, but also revealed significantly higher expression levels of several genes in tick cells as opposed to human ECs.

\section{Quantitative RT-PCR based validation of differential regulation of coding transcripts}

To further confirm differential, host niche-dependent expression of $R$. conorii coding genes observed in our deep sequencing data, we selected $R C 0511$ and RCO149 as the respective candidates differentially upregulated during the infection of tick and human cells (Tables 3 and 4). Our rationale for choosing these genes was based upon their protein function. The homologs of RC0511 are putatively annotated as transcriptional regulators belonging to the AbrB family, whereas RC0149 is an acetate kinase (EC 2.7.2.1) involved in the synthesis of acetyl-coA required 
for carbohydrate and lipid metabolism. Because previous studies have suggested an important role for the host temperature as a determinant of rickettsial gene transcription and tick cells are routinely maintained and infected at $34^{\circ} \mathrm{C}$, we infected host HMECs at both $34^{\circ} \mathrm{C}$ and $37^{\circ} \mathrm{C}$ to delineate the potential influence of temperature on gene expression. As expected, RC0149 was significantly upregulated during the infection of HMECs when compared to AAE2 cells, and temperature $\left(34^{\circ} \mathrm{C}\right.$ vs $\left.37^{\circ} \mathrm{C}\right)$ had no significant effect on the expression of this transcript. At $24 \mathrm{~h}$ post-infection, RCO149 mRNA abundance displayed an average increase of 4-fold in HMECs (Fig. 1). On the other hand, expression of RC0511 was slightly influenced by changes in temperature as indicated by higher expression $(p<0.05)$ in HMECs infected at $37^{\circ} \mathrm{C}$ versus those at $34^{\circ} \mathrm{C}$. Finally, RC0511 was expressed at much higher levels in tick cells at both $3 \mathrm{~h}$ and $24 \mathrm{~h}$ post-infection when compared to HMECs at the corresponding temperatures, thus suggesting contributory roles for both the host cell niche and its growth temperature in the differences in mRNA expression (Fig. 1).

\section{Identification of transcription start sites}

As rickettsial genomes harbor $\mathrm{A}-\mathrm{T}$ rich polymorphic tracks resulting in the presence of spurious promoters and several genes are under the regulation from multiple promoters, we performed $5^{\prime}$-terminator exonuclease (TEX) treatment to enrich RNA for primary transcripts to identify transcription start sites (TSSs) in $R$. conorii genome. Sequencing following TEX treatment yielded an average of 82 and 85 million reads from infected tick cells and human ECs, respectively, of which 2.5 and 3.3 million reads mapped to $R$. conorii. The percentage of reads mapping to rickettsial genome is attributed to the limited efficiency of enrichment procedures, resulting in incomplete removal of eukaryotic host mitochondrial and noncoding RNAs lacking polyA tail, and bacterial ribosomal RNAs, and is in agreement with previous studies $[23,26]$. Using TSSAR, we classified TSSs as promoter (pTSS), intergenic (iTSS), orphan (oTSS), antisense intergenic (AiTSS), or antisense downstream (AdTSS) based on the genomic location (Fig. 2a). A total of 3903 and 2555 TSSs were identified during in vitro infection of AAE2 and HMECs with $R$. conorii (Fig. 2b and c; Additional files 4 and 5). Of these, nearly $76 \%$ were classified as either intergenic or antisense intergenic and another $10-11 \%$ were categorized as 'orphan' TSSs depending on their genomic location (Fig. $2 b$ and c). Our findings further revealed 214 and 181 pTSSs for coding transcripts in the tick vector and human host cells, respectively, of which 75 genes exhibited a difference in their TSS depending on the host niche (Additional file 6). The average length of 5'UTR was 80 and 71 bases for rickettsial coding transcripts in tick and human host cells, respectively. Of the 75 mRNA transcripts which exhibited a difference in their TSSs, RC0368 (genomic location:
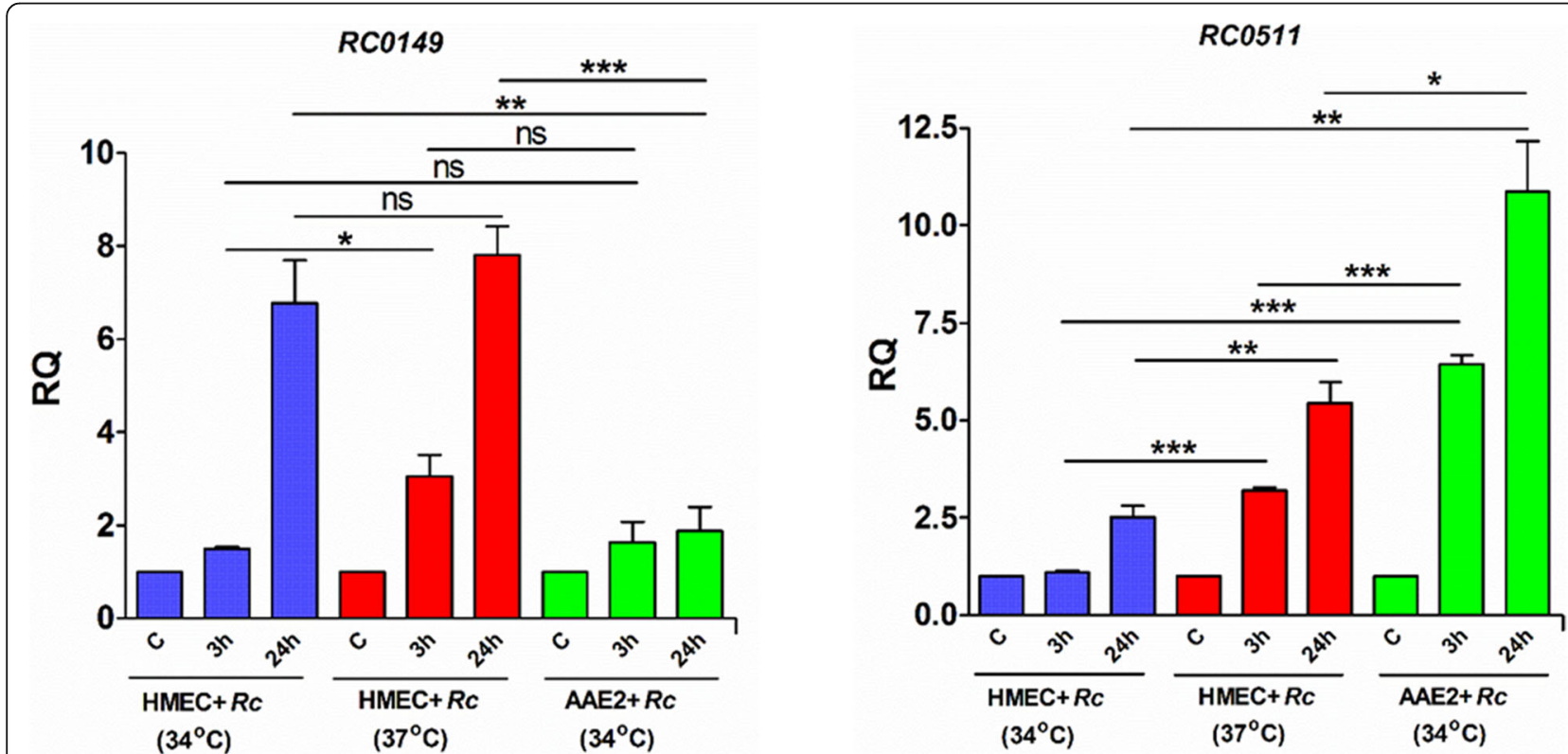

Fig. 1 Quantitative PCR based validation of $R$. conorii coding genes differentially expressed during host and tick cell infection in vitro. $R$. conorii infected HMECs were maintained at either $37^{\circ} \mathrm{C}$ or $34^{\circ} \mathrm{C}$, and AAE2 cells infected with $R$. conorii were maintained at $34{ }^{\circ} \mathrm{C}$ for the entire duration of the experiment. Total RNA was extracted at $15 \mathrm{~min}, 3 \mathrm{~h}$ and $24 \mathrm{~h}$ post infection, DNasel treated, and reverse transcribed as described. Expression profile of RC0149 and RC0511 was quantified using gene-specific primers and 16S rRNA as endogenous control. Human and tick cells infected with $R$. conorii for 15 min served as baseline control and fold changes were calculated as described in methods. Data from three independent replicates is presented as mean \pm SEM. ns $=$ not significant, ${ }^{*} p<0.05,{ }^{* *} p<0.01,{ }^{* *} p<0.001$ 
A

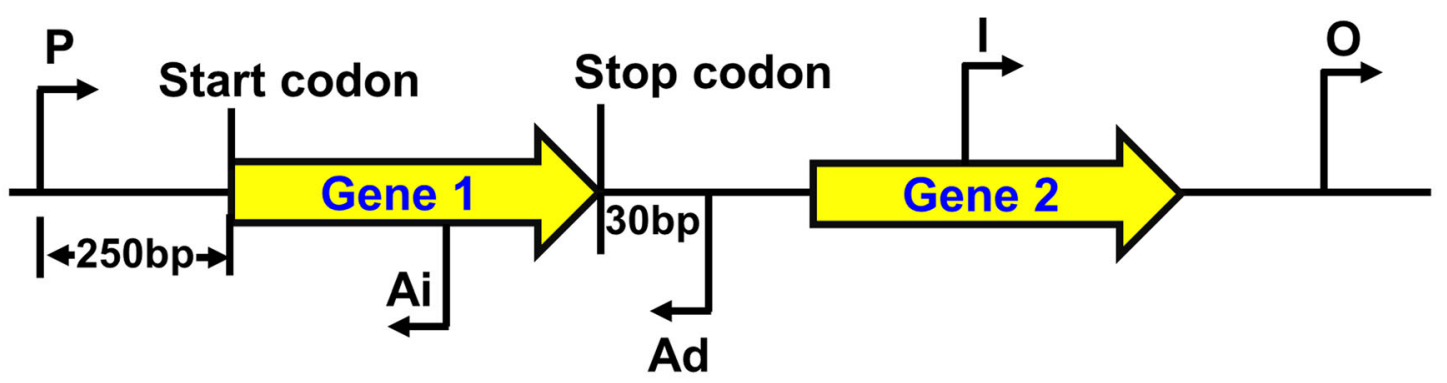

B

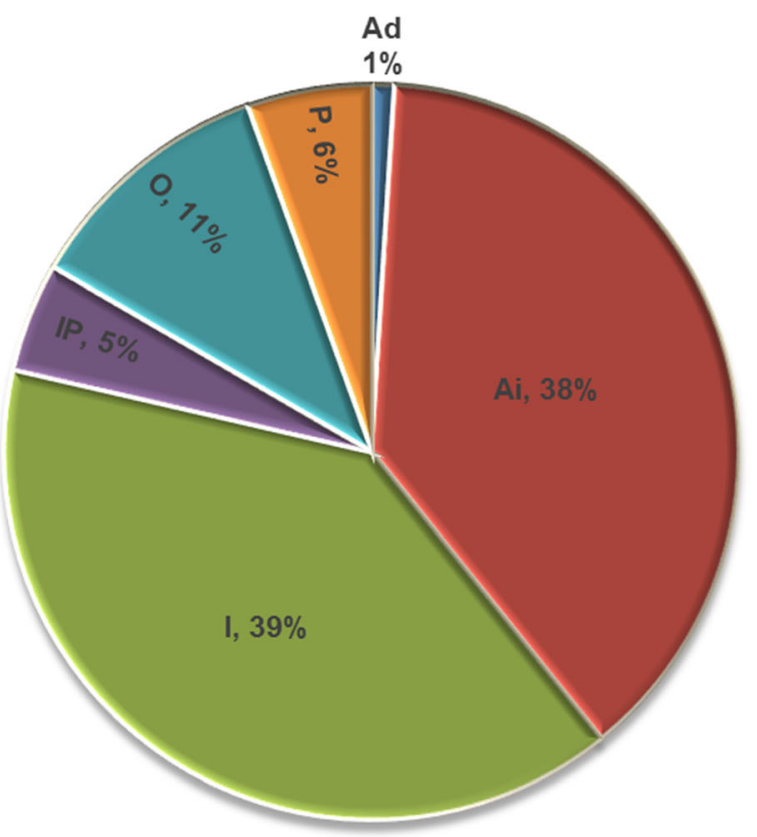

Total: 3903
C

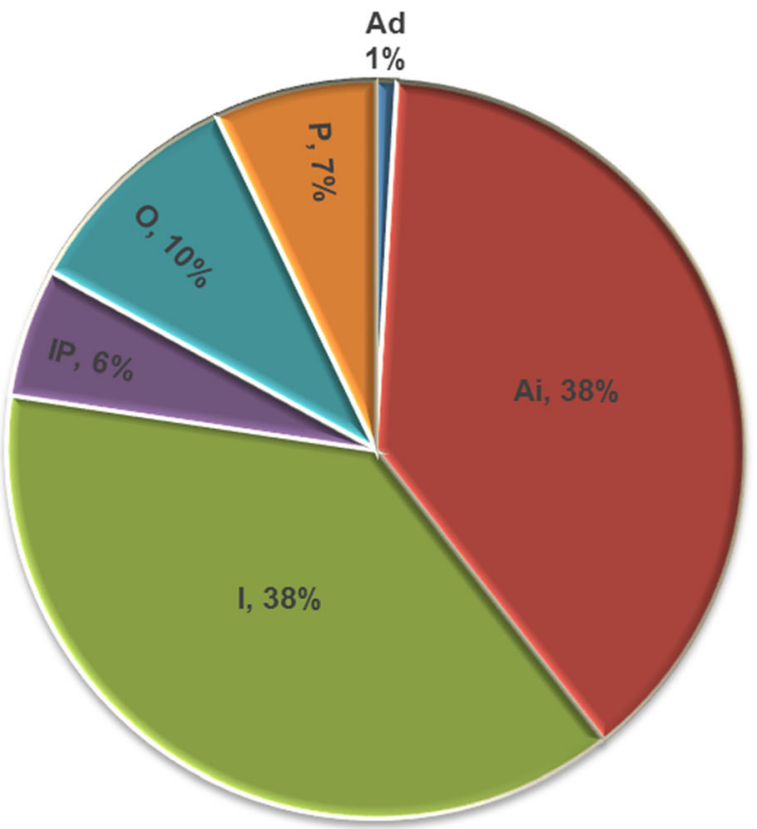

Total: 2555

Fig. 2 a: Identification and distribution of TSS in R. conorii during infection of host and tick cells, in vitro. a: Schematic showing the genomic location and classification of TSS. TSS were categorized as promoter (P), intergenic (I), orphan (O), antisense intergenic (Ai), and antisense downstream intergenic (Ad) based on their genomic location and distance from the translation start and stop positions of the respective gene. $\mathbf{b}$ and $\mathbf{c}$ : Distribution of different categories of TSS identified by TSSAR in R. conorii during the infection of tick AAE2 $\mathbf{b}$ and host HMECS $\mathbf{c}$, in vitro. A total of 3903 and 2555 TSS were identified in R. conorii during infection of tick vector and human host cells, respectively. Majority of TSS (> 75\%) were categorized as either intergenic or antisense intergenic depending on their genomic position

365526-366,383) exhibited the largest difference of 175 bases, yielding a longer transcript in tick cells (TSS: 366698) than in HMECs (TSS: 366523). Interestingly, RC1282 encoding for an adhesin Adr2 had a pTSS located 111 bases upstream of the translation start site during infection of AAE2 cells in comparison to only 12 bases upstream in HMECs (Additional file 6), indicating the use of alternative TSSs depending on the host cell. Collectively, our data reveal extensive antisense transcription in $R$. conorii irrespective of the host cell type, pTSSs for $\sim 16 \%$ of the coding transcripts expressed in tick and human cells as the host, and existence of alternative pTSSs for several genes depending on the host niche.

\section{Identification of $R$. conorii sRNAs and riboswitches} expressed during tick cell infection in vitro

We have previously reported on the expression of small noncoding RNAs in $R$. conorii genome during in vitro infection of mammalian host cells [24]. To compare and contrast the noncoding landscape during infection of human host and tick vector cells, we performed deep sequencing of enriched bacterial transcriptome from 
HMECs and AAE2 cells infected with $R$. conorii for $24 \mathrm{~h}$. The reads trimmed for base quality control were mapped to $R$. conorii genome (PATRIC annotation) for identification of sRNAs (both cis- and trans-acting) and riboswitches. In this study, we confirmed the expression of $43 R c \_s R s$ reported previously [24], and identified an additional $32 R c_{\_}$sRs found to be abundantly expressed in tick AAE2 cells (Fig. 3, Additional file 7). The expression of all of these sRNAs, including $16 R c_{-}$sRs categorized as cis-acting (antisense of a coding gene) and 12 as trans-acting (intergenic) based on their location of origin (Additional file 7) were determined to be below the limit of detection in HMECs. Also, Rc_sR59 was identified as a riboswitch based on its location in the $5^{\prime}$-UTR region of RC0441, a hypothetical protein with considerable homology to the flagellar hook associated protein FlgK in Bacillus species (e-value 9e-06, 30\% identity). In addition, three sRNA candidates (Rc_sR45, sR46, and sR62) were classified as both cis- and trans-acting owing to partial overlap with the neighboring (up or downstream) gene and the intergenic region, suggesting the possibility of regulating both the overlapping gene (antisense to sRNA) by direct base pairing and distant genes via partial base pairing. Further, 17 of the $32 R c_{-}$sR's were present on the leading strand and the remaining 15 originated from the lagging strand (Additional file 7). The average length of $R c_{-}$sR's abundantly expressed during tick cell infection was 300 bases, with Rc_sR48 being the shortest (108 bases) and Rc_sR66 the longest (526 bases). Notably, cis-acting sRNAs were found on the anti-sense strands of several important genes encoding for outer membrane proteins (rOmpA, rOmpB and Sca4), an inner membrane protein of type IV secretion system (VirB6), protein translocase (SecF), proton/glutamate symporter (GltP), and prolipoprotein diacylglyceryl transferase (Igt) (Additional file 7). Thus, comparative deep sequencing enabled the identification of a number of new $R c_{-}$sR candidates abundantly expressed in tick host cells, implicating a role for their contributions to differential regulation of coding transcriptome during host-pathogen and vector-pathogen interactions.

\section{Validation of SRNA expression during $R$. conorii expression of host and tick cells}

To further validate $R c_{-}$sR's identified to be expressed during $R$. conorii infection of tick cells, expression of three trans-acting sRNAs (Rc_sR61, sR71, and sR74) was assessed by quantitative RT-PCR using sRNA specific primers and 16S rRNA as an endogenous control. For comparative analysis, $R c_{-}$sR expression was measured at $3 \mathrm{~h}$ and $24 \mathrm{~h}$ post-infection in HMECs grown and maintained at $34{ }^{\circ} \mathrm{C}$ and $37{ }^{\circ} \mathrm{C}$, and in AAE2 cells maintained at $34^{\circ} \mathrm{C}$. The temperature had no influence on the transcript abundance of $R c_{-}$sR7 1 and $R c_{-} \mathrm{sR74}$, but $R c_{-}$ sR61 displayed a statistically significant difference in its expression at $3 \mathrm{~h}$ in HMECs infected at $34^{\circ} \mathrm{C}$ versus $37^{\circ} \mathrm{C}$ (Fig. 4). All three sRNAs tested were highly upregulated at both $3 \mathrm{~h}$ and $24 \mathrm{~h}$ post-infection during $R$. conorii infection of AAE2 cells when compared to HMECs as the host cells. At $24 \mathrm{~h}$ post-infection, expression levels in tick cells were higher by an average of 3-5 fold than those seen in HMECs, corroborating our findings from the deep sequencing approach (Fig. 4).

\section{Comparative analysis of 6S RNA expression during HMEC and AAE2 infection}

6S RNA (ssrS) is a small RNA regulator of RNA polymerase highly conserved in most bacteria, including all Rickettsia species. We have previously reported on the presence of $R$. conorii 6S RNA (Rc_sR36) transcripts during the infection of HMECs and confirmed its expression by Northern blotting [24]. To further compare and quantify its expression during in vitro infection of mammalian host vis-à-vis tick cells, we performed a Taqman based RT-qPCR assay on total RNA extracted at different times ranging between $15 \mathrm{~min}$ and $24 \mathrm{~h}$ postinfection. Owing to the obligate intracellular lifestyle of Rickettsia species, the earliest time point of $15 \mathrm{~min}$ was used as the baseline control. 6S RNA was significantly upregulated at all times compared to its basal level of expression (at $15 \mathrm{~min}$ ) in infected HMECs, with the highest increase of $\sim 10$-fold at $24 \mathrm{~h}$ (Fig. 5a). In sharp contrast, 6S RNA expression in tick cells remained unchanged in comparison to the baseline control at different times post-infection, suggesting differential regulation during host-pathogen and vector-pathogen interactions, in vitro (Fig. 5a). The secondary structure of $R$. conorii $6 \mathrm{~S}$ RNA (Rc6S), as determined by RNA-fold, resembled that of E. coli $6 \mathrm{~S}$ RNA (Ec6S). Similar to Ec6S, Rc6S RNA also displays a central bulge of single stranded nucleotides critical for the binding to sigma 70 transcription factor and forms a double stranded stem like structure with minor bulges (Fig. 5b).

\section{Discussion}

In this study, we have analyzed the coding and noncoding transcriptomes of $R$. conorii during hostpathogen and vector-pathogen interactions, in vitro. Using a high throughput RNA sequencing approach, we have identified differentially expressed genes depending on the host niche and 32 novel $R$. conorii sRNAs abundantly expressed during tick cell infection as compared to host HMECs. Additionally, we performed enrichment of primary transcripts using $5^{\prime}$ terminator exonuclease to determine the transcription start sites for 214 and $181 R$. conorii genes expressed during infection of vector and human host cells, respectively. 


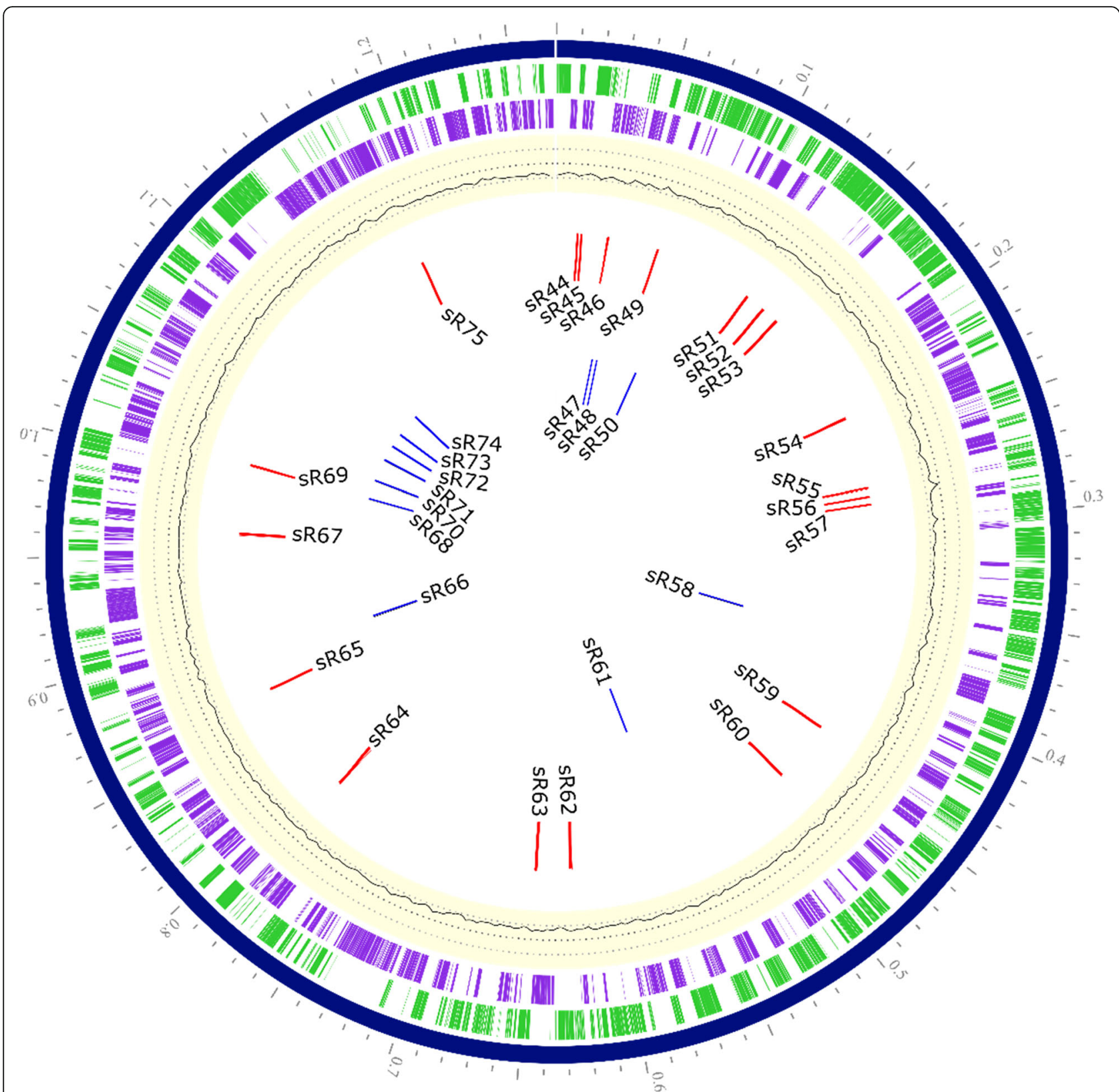

Fig. 3 Circular chromosome map of $R$. conorii showing the genomic location of Rc_sRs identified in this study. The genome map of $R$. conorii was generated using PATRIC genome annotation (Genome ID: 27944.4) and different circles with bars represent: (1) Bright green (outermost): $R$. conorii coding genes annotated on the sense strand, (2) Purple: R. conorii coding genes annotated on the anti-sense strand, (3) Light yellow: GC skew, (4) Red bars: all cis-acting Rc_sR's and riboswitch (Rc_sR59), and (5) Blue bars: all trans-acting Rc_sR's identified in this study. The cis/trans acting sRNAs (RC_sR45, sR46 and sR65) are also shown with red bars on second circle (inside to outside). RC_sR1 through sR43 reported in our previous study [24] are not shown here

As obligate intracellular pathogens, a majority of spotted fever group rickettsiae are transmitted to humans via a tick bite. Although some Rickettsia species, example $R$. rickettsii, are detrimental to ticks infected by transovarial transmission in nature, a majority are known to persist and survive in infected vectors and lead to serious disease in humans [27]. However, the mechanisms by which pathogenic Rickettsia species adapt to different host environments remain obscure. Our findings reveal that while the same core set of genes are abundantly expressed during the infection of both cell types (Tables 1 and 2), a greater number of other $R$. conorii genes are transcribed above the limit of detection and differentially expressed during the infection of tick vector cells in direct comparison to human endothelial cells, in vitro (Additional file 2). Interestingly, RC0497 was determined to be the most abundantly 


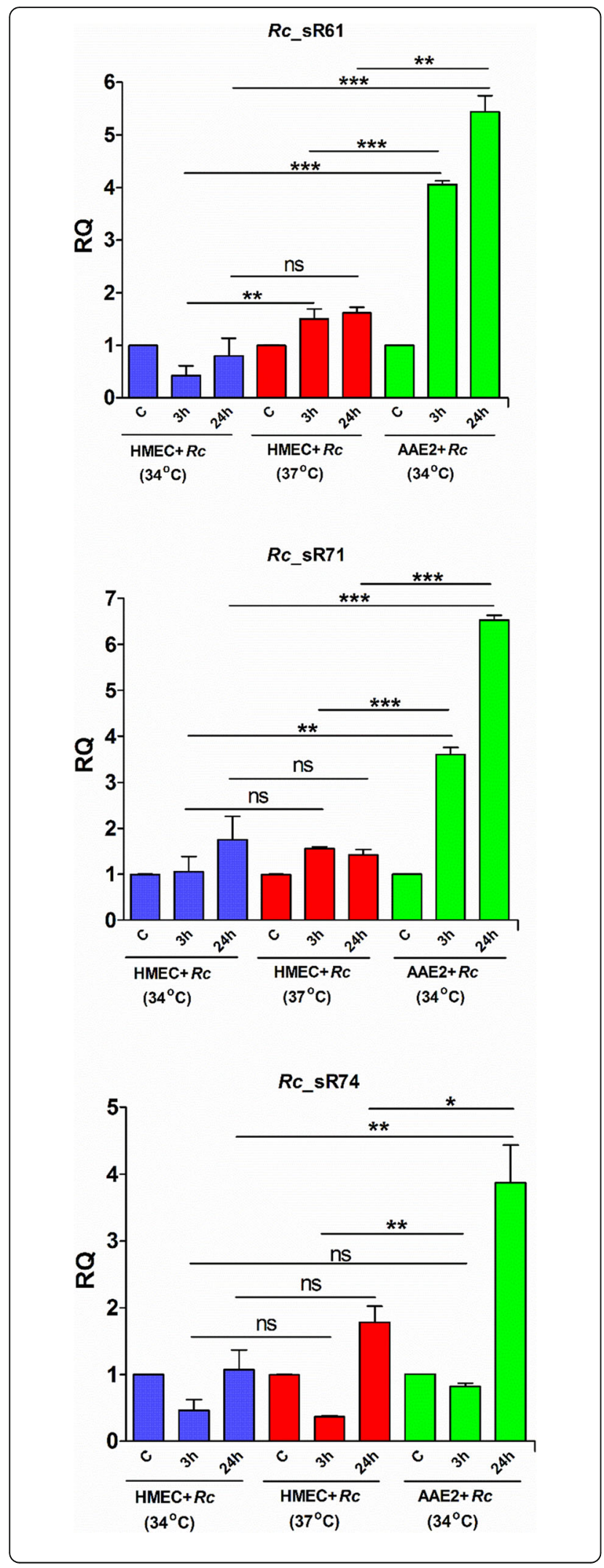

Fig. 4 Quantitative PCR based validation of R. conorii RC_sRs highly expressed during tick cell infection in vitro. $R$. conorii infected HMECs were maintained at either $37^{\circ} \mathrm{C}$ or $34^{\circ} \mathrm{C}$, and AAE2 cells infected with $R$. conorii were maintained at $34^{\circ} \mathrm{C}$ for the entire duration of the experiment. Total RNA was extracted at $15 \mathrm{~min}, 3 \mathrm{~h}$ and $24 \mathrm{~h}$ post infection, DNasel treated and reverse transcribed as described. Expression profile of Rc_sR61, sR71 and sR74 which were highly expressed during tick cell infection and identified in our RNA seq data were quantified using sRNA-specific primers and $16 \mathrm{~S}$ rRNA as housekeeping control. Human and tick cells infected with $R$. conorii for $15 \mathrm{~min}$ served as baseline control and fold changes were calculated as described in methods. Data from three independent replicates is presented as mean \pm SEM. ns $=$ not significant, ${ }^{*} p<0.05$, ${ }^{* *} p<0.01,{ }^{* * *} p<0.001$

expressed gene in both cell types (Tables 1 and 2). Recently, we have characterized RC0497 as an ampD domain containing $\mathrm{N}$-acteylmuramoyl-L-alanine amidase involved in peptidoglycan hydrolysis and demonstrated its localization on the septal regions in dividing bacteria and on the membranes of vesicles protruding from the rickettsial cell wall [28]. A simultaneous study has further revealed that RC0497 is also secreted into the culture supernatants during infection of endothelial cells in vitro and is readily detectable in the serum of infected patients, projecting it as a promising candidate for the design and development of rapid diagnostics [29]. Additionally, heat shock chaperone (groEL), cold shock protein of CSP family $(\operatorname{csp} A)$, CarD like transcriptional regulator, and anti-toxins ( $v a p B$ and anti-toxin of relE) were ubiquitously expressed in both infected HMECs and tick cells. Previous studies have reported constitutive expression of rickettsial groEL during active growth conditions (mid-log phase), down-regulation during slow growth and starvation, and up-regulation during heat shock [5, 30,31]. The groEL is an essential molecular chaperone required for proper folding of proteins. In endosymbiotic bacteria, groEL is presumed to play a vital role in restoring bacterial fitness, which is compromised due to the accumulation of mutations arising from the bottlenecks experienced during transovarial transmission [32-34]. On the other hand, proteins belonging to the CSP family are activated during oxidative, osmotic, as well as cold stress conditions, and required for bacterial adaptation and intracellular survival [35-37]. For instance, deletion of CSP family proteins in Listeria monocytogenes results in increased susceptibility to oxidative stress and impaired host cell invasion and intracellular growth [38]. Also, $\operatorname{csp} A$-lacking mutants of Brucella display differential expression of 446 genes involved in energy metabolism and the biosynthesis of amino- and fatty acids. Notably, genes involved in type IV secretion system are also downregulated, indicating its role in virulence, metabolism, and adaptations to host microenvironment $[39,40]$.

Spotted fever group rickettsiae employ actin-based motility for intracellular movements and intercellular spread. In this regard, bacterial RickA localized at the 
A

6S RNA

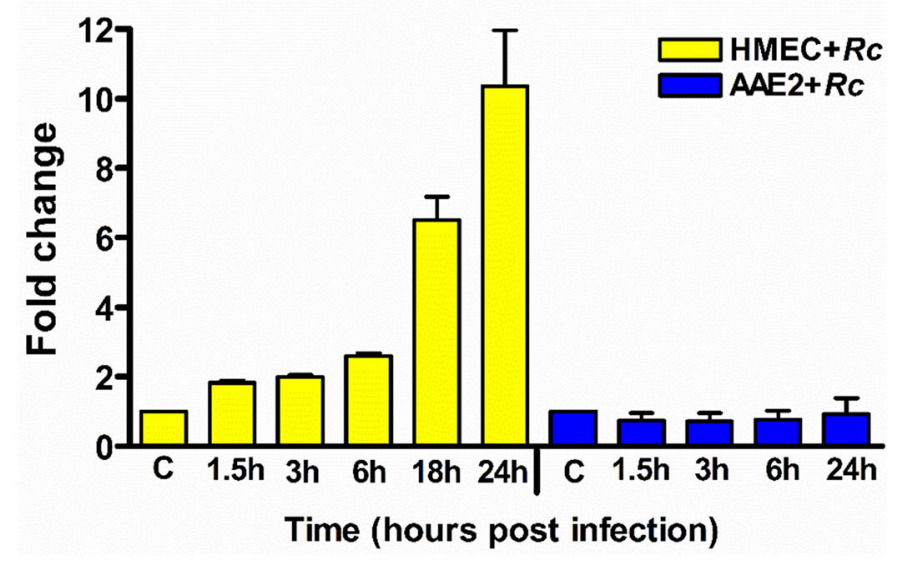

B

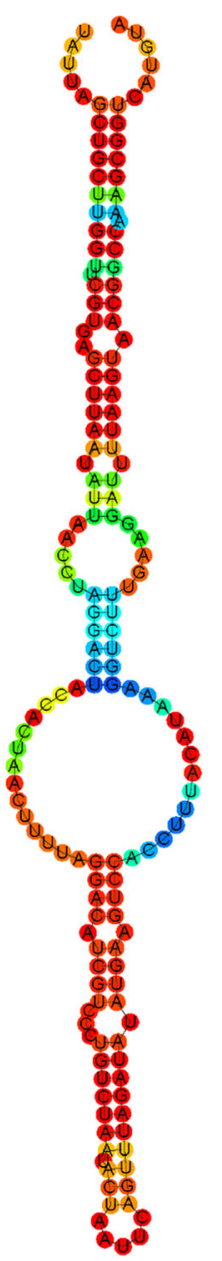

Fig. 5 a: Expression profile and secondary structure of R. conorii $6 S$ RNA. A. Expression of 65 RNA during the infection of HMECS and tick cells in vitro. HMECs and AAE2 cells were infected with $R$. conorii $(\mathrm{MOI}=50)$ and total RNA was extracted at different time interval between $0.5 \mathrm{ho} 24 \mathrm{~h}$ post infection. Total RNA was DNasel treated, reverse transcribed, and expression of $6 \mathrm{~S}$ RNA was assessed by Taqman based quantitative PCR using $6 \mathrm{~S}$ RNA specific primers and probe, and 16S rRNA as internal control. The data was calculated using expression at $0.5 \mathrm{~h}$ as baseline control. 6S RNA was significantly upregulated $(p<0.05)$ at all time point during the infection of HMECs, while steady state expression with no significant change was observed during tick cell infection. Data from three independent replicates is presented as mean \pm SEM. $\mathbf{b}$. Predicted secondary structure of 6S RNA. The secondary structure of R. conorii 6S RNA predicted by RNAfold web server (University of Vienna) resembles the conserved structure observed for most bacterial 6S RNAs. The color coding on bases indicate base pairing probability of 0 to 1 (purple to red) 
pole has been implicated in the activation of host Arp2/ 3 complex and formation of actin tails for dissemination during early stages of infection [41]. Thus, our finding of abundant expression of rickA irrespective of the host cell type is not surprising. Earlier studies on $R$. parkeri rick $A$ and sca 2 deletion mutants have documented their ability to spread to all organs of A. maculatum, but exhibit significantly lower rickettsial burden in comparison to the wildtype, indicating that these genes are necessary for efficient dissemination to different tissues of the host [42]. At least five bicistronic modules coding for a stable toxin and a liable antitoxin have been reported in most rickettsial genomes. Among them, VapC toxin secreted into the cell cytosol and exhibiting RNase activity is presumably involved in mediating the deleterious effect of ciprofloxacin during the infection of host cells, in vitro [43, 44]. Furthermore, a role for the relBE module in tolerance of $E$. coli to antibiotics has also been suggested $[45,46]$. It is, therefore, possible that Rickettsia ubiquitously express these genes irrespective of the host cell type to facilitate their spread, persistence, and tolerance of host and environmental stress responses.

We identified 132 and 305 differentially upregulated genes $\left(\log _{2}\right.$ fold change $\left.\geq 2.0\right)$ in human ECs and tick AAE2 cells, respectively. Of these, nearly 49\% (61 of 125) encoding for hypothetical proteins in $R$. conorii were uniquely expressed in tick cells (Additional file 2). Consistent with this finding, $R$. rickettsii transcripts for numerous hypothetical proteins putatively encoding for iron permease, thioredoxin, and ankyrin repeat proteins undergo differential modulation due to temperature changes and blood feeding in tick vectors $[7,8]$. In further agreement with earlier reports showing increased expression of type IV secretion components and putative effectors of $R$. rickettsii in tick vectors during blood meal [8], we also observed up-regulation of transcripts encoding for VirB6, VirB8, and VirB9, ankyrin repeat proteins (Ank proteins), tetratricopeptide repeat proteins (TPR), acid phosphatase, and metalloprotease during tick cell infection (Additional file 2). Evidence suggests that metalloproteases and Ank proteins of several bacteria, including Rickettsia species, are secreted into extracellular milieu, interact with host components, and regulate host immune responses [47, 48]. As a predicted cysteine protease secreted via type IV secretion system, RARP-2 (rickettsial ankyrin repeat protein-2) has recently been documented for its involvement in the fragmentation of trans-Golgi network, resulting in the disruption of protein trafficking to plasma membrane [49]. Orientia Ank proteins are known to modulate NF- $\mathrm{kB}$ transcriptional activation, protein secretion, endoplasmic reticulum (ER) stress, SCF1 ubiquitin ligase assembly, and Golgi to ER retrograde trafficking, thus impacting the replication and/or pathogenesis in the host cell [50-52]. Similarly, metalloproteases produced by several bacteria contribute to a wide array of pathomechanisms such as hemorrhagic tissue damage, increased vascular permeability, degradation of proteins and peptides for bacterial nutrition, and adhesion to and invasion into host cells [53]. For example, Serratia grimesii metalloprotease grimelysin is secreted through outer membrane vesicles, hydrolyzes actin, and aids in bacterial invasion of host cells [54]. The E. coli SslE, a zinc metalloprotease with mucinase activity, facilitates penetration of mucus layer and is involved in adhesion of bacteria to host cell [55]. TPR containing proteins in bacterial pathogens function as determinants of virulence, host cell adhesion and intracellular survival, inhibition of phagosomal maturation, transduction of stress signals, and chaperone activity [56]. For instance, Pseudomonas aeruginosa $\mathrm{PcrH}$, a TPR domain containing protein, functions as a class II chaperone and facilitates stabilization of translocators (PopB and PopD) essential for the translocation of toxins into host cytosol, and protein kinase G (PknG) of Mycobacterium tuberculosis secreted into macrophages inhibits phagosome-lysosome fusion to ensure intracellular survival and bacterial replication $[57,58]$. Further, acid phosphatases from Francisella tularensis secreted into host cytoplasm also function as virulence factors involved in the inactivation of NADP $\mathrm{H}$ oxidase and inhibition of oxidative burst in host macrophages [59]. Thus, upregulation of genes coding for TPRs, metalloproteases, and acid phosphatases in infected tick cells may modulate host responses (example, prevention of oxidative burst) to facilitate rickettsial colonization and persistence in arthropod vectors. Since previous studies have demonstrated considerable differences in rickettsial gene expression between controlled (in vitro) and natural (in vivo) conditions as a consequence of temperature shift and a majority of $R$. rickettsii genes are differentially modulated by feeding, target tissue (salivary glands or midgut), and gender of the tick vector $[5,7,8]$, studies to further comprehend the roles of these proteins in tick vectors during natural transmission will provide a better understanding of the rickettsial adaptation mechanisms during host-pathogen and vector-pathogen interactions. An important consideration in this regard is that acquisition of bacteria by tick vectors during natural blood feeding may vary greatly and environmental stimuli may also have a profound impact on pathogen intake, maintenance and transmission as part of the natural life-cycle.

We employed the standard approach of $5^{\prime}$-terminator exonuclease treatment to enrich primary transcripts and to identify $R$. conorii transcription start sites during the infection of human ECs and tick vector cells. Regardless of the host cell type (HMECs or AAE2 cells), nearly 76\% of the total TSSs identified in $R$. conorii are either categorized as antisense or internal based on their genomic origin (Fig. 2b and c; Additional files 4 and 5). The 
existence of a large proportion of antisense transcription in organisms belonging to archaea, prokaryotes, and eukaryotes is now well appreciated [60-62]. For example, differential RNA sequencing of $E$. coli grown in three different conditions has led to the identification of a total of 14,868 TSSs, of which nearly $74 \%$ correspond to either potential antisense RNAs or are internal to annotated genes [63]. Genome wide mapping of TSSs in Leptospira interrogans has also identified more than 2800 TSSs, of which $12 \%$ are classified as antisense TSS and 53\% designated as internal [64]. Similarly, 13 and 63\% of the total 6042 TSSs identified in Borrelia burgdorferi during the infection of mammalian host have also been classified as antisense and internal TSSs, respectively [65]. Of the 1576 annotated ORFs in Helicobacter pylori, 46\% (721) of the genes contain at least one antisense TSS and nearly $17 \%$ of the 2496 TSSs are categorized as intergenic based on their genomic location [66]. Although these and our current findings reveal the prevalence of antisense transcription in most organisms including $R$. conorii, the biogenesis and roles of antisense transcripts in the regulation of the coding transcriptome is not yet clear. Antisense transcription is generally considered a 'biological noise' originating due to inefficient transcriptional termination by Rho-independent terminators and the presence of spurious promoters arising from point mutations, especially in AT rich genomes like that of Rickettsia species [67]. Nevertheless, antisense transcripts are known to act as genetic switches controlling bacterial competence, virulence, and regulation of toxins [68-70]. Additionally, several antisense RNAs are known to function as post-transcriptional inducers or inhibitors of gene expression and protein translation, and as regulators of plasmid copy numbers through inhibition of primer maturation, thus impacting several cellular functions, including biofilm formation, quorum sensing, and toxin synthesis [71]. For example, while cisencoded antisense RNA of mucD (mucD_AS) regulates $m u c D$ expression and induces biofilm formation in Pseudomonas aeruginosa, micF as an asRNA in E. coli inhibits OmpF by destabilizing the mRNA and inhibiting translation [72, 73]. It is now also evident that several antisense promoters in $E$. coli are functional and involved in the fine tuning of gene expression [74]. Thus, it is likely that although antisense transcription in bacterial genomes is pervasive, some of these transcripts encode for a bona fide function and play a vital role in the survival, fitness, and pathogenesis of the organism.

We have identified primary TSSs for $16 \%$ of the genes, of which $75 R$. conorii coding transcripts exhibit difference in their pTSS during in vitro infection of human host and tick vector cells (Additional file 6). The occurrence of secondary TSS (sTSS) is also common in most bacterial and archaeal genomes. For example, of the 14,
868 TSSs in E. coli, 1707 and 850 have been classified as primary and secondary TSSs, respectively [63]. Similarly, $\sim 2300$ and $\sim 3100$ TSS are categorized as sTSS in Leptospira grown at $30^{\circ} \mathrm{C}$ and $37^{\circ} \mathrm{C}$, respectively, indicating a role for environmental cues in the determination of transcription start sites [64]. In $R$. prowazekii, the citrate synthase gene is under the control of two promoters and our recent transcriptomic analysis revealed that 18 genes exhibit differences in their TSSs during rickettsial infection of HMECs and AAE2 cells $[25,75]$. Consistent with our previous report for $R$. prowazekii, the coding transcripts expressed in $R$. conorii during the infection of tick vector cells were longer than those in human host cells. It is thus plausible that the length of $5^{\prime}$-UTR may influence the half-life of mRNA and have an impact on translational efficiency. Further studies using reporter constructs are likely to shed light on the roles of alternative/secondary TSSs of rickettsial transcripts in transcriptional regulation during rickettsial persistence and pathogenesis in the tick vector and human host, respectively.

One of the key findings in this study is the identification of 31 novel cis- or trans-acting Rc_sR's and one riboswitch abundantly expressed in $R$. conorii during the infection of tick vector cells. Of these, expression of three trans-acting $R c \_s R$ 's [sR61, sR71 and sR74] was further confirmed by quantitative RT-PCR (Figs. 3 and 4, Additional file 7). These results are in congruence with the published literature reporting exclusive expression of selective bacterial small RNAs in response to external stimuli, such as stress, nutrient starvation, temperature shift, and host environment [18, 19, 21]. In $R$. prowazekii, 67 cis-acting and 26 trans-acting sRNAs were abundantly expressed only during the infection of tick AAE2 cells [25]. Buchnera is an obligate nutritional endosymbiont maintained by transovarial transmission in aphids. This bacterium is shown to express $26 \%$ of its sRNA repertoire based on the life stage of the aphid host. Furthermore, 21\% of Buchnera sRNAs are expressed depending on the host plant, indicating the bacterial potential to alter its transcriptome based on the availability of nutrients from the aphid host [76, 77]. In Borrelia burgdorferi, nearly $43 \%$ of sRNAs are demonstrated to be temperature dependent, of which 128 and 303 sRNAs are upregulated at $23^{\circ} \mathrm{C}$ (ambient temperature of tick vector) and $37^{\circ} \mathrm{C}$ (temperature of the human host), respectively. Interestingly, two antisense sRNAs regulating bba66, a gene required for eukaryotic host infection through tick transmission, are upregulated at $37^{\circ} \mathrm{C}$, indicating a potential role for these sRNAs in the regulation of coding transcriptome during host-pathogen interactions [18]. Eighty-four sRNAs in E. coli are differentially expressed solely during fermentation, yet 139 sRNAs involved in biofilm formation, motility, regulation of outer membrane proteins, and maintenance of cell envelope are 
significantly up- or down-regulated during chemical stress [78]. Therefore, it is likely that $32 R c \_s R ' s$ identified in this study, play an important role in regulating rickettsial transcriptome during vector-pathogen interactions. Despite the absence of hfq, an RNA chaperone involved in sRNAmRNA binding, in rickettsial genomes, we have previously confirmed the interactions between $R c \_s R 42$ and $c y d A$ mRNA in vitro, suggesting the possibility of direct binding as a mechanism of action by rickettsial sRNAs [24]. Further studies focused on the identification and functional characterization of target genes regulated by these sRNAs will shed light on the roles of $R$. conorii sRNAome in host-pathogen-vector interplay.

Another striking and intriguing observation of this study is the differential expression of 6S RNA during the infection of human versus tick cells. While 6S RNA $(s s r S)$ expression steadily increased in HMECs, no significant differences compared to the basal levels were observed during the infection of tick cells (Fig. 5). It is now increasingly evident that $6 \mathrm{~S}$ RNA in a number of bacteria is differentially expressed depending on the growth stage. For instance, E. coli and Legionella $6 \mathrm{~S}$ RNA accumulates at $\sim 10$ fold higher levels during stationary growth phase, while the Bacillus 6S RNA expression changes only $2-3$ fold between the exponential and stationary phases [79]. Similarly, 6S RNA expression in $R$. prowazekii doubles at 48-72 $\mathrm{h}$ post-infection in comparison to early stages ( 1.5 to $3 \mathrm{~h}$ ), during the infection of host endothelial cells, in vitro [22]. The Coxiella $6 \mathrm{~S}$ RNA also shows the highest accumulation in its small cell variant form at 14 days post-infection [80]. However, Wolbachia 6S RNA accumulates at higher levels during fast replication and infection of germ line cells, compared to stationary growth and infection of somatic cells, respectively [81]. In Borrelia, 6S RNA exhibits highest expression levels in Ixodes unfed nymphs compared to fed nymphs and ssrS deletion mutant is compromised in infectivity of mice. Interestingly, despite being seropositive, the number of antigenic proteins reacting with murine immune system are considerably less in the $\Delta s s r S$ mutant compared to wild type or ssrS complemented strain, implicating a role for $6 \mathrm{~S}$ RNA in the regulation of the expression of genes targeted by the murine adaptive immune system [82].

Functional and crystallographic studies have shown $6 \mathrm{~S}$ RNA to be a global transcriptional regulator, which tightly binds to housekeeping holoenzyme $\mathrm{E \sigma}^{70}$ with high specificity and is involved in the regulation of transcription of genes with $\sigma^{70}$ dependent promoters. Although initial studies showed downregulation of genes containing $\sigma^{70}$ promoters due to increased expression of 6S RNA, later findings revealed that accumulation of $6 \mathrm{~S}$ RNA can result in both up and downregulation of several genes in a promoter-specific manner [79]. The deletion of E. coli 6S RNA resulted in increased expression of genes under $\mathrm{E}^{70}$ promoters, while genes regulated by $\mathrm{E \sigma}^{38}$ promoters were downregulated [83]. Under normal growth conditions, the cellular concentration of sigma factors exceeds RNA polymerase (E) concentration resulting in increased competition among the sigma factors to bind to $\mathrm{E}$, and most abundantly expressed $\sigma^{70}$ exhibiting higher affinity $\left(K_{\mathrm{d}}=0.26 \mathrm{nM}\right)$ for $\mathrm{E}$ can actively prevent binding of other sigma factors exhibiting low affinity (example: $\sigma^{38}, K_{\mathrm{d}}=4.26 \mathrm{nM}$ ) to compete for RNA polymerase. Thus, increased expression of 6S RNA can sequester E $\sigma^{70}$ allowing other sigma factors including $\sigma^{38}$ to compete more effectively for binding to $E$, thus allowing for increased expression for genes regulated by these sigma factors [84]. Though $E$. coli encodes for seven sigma factors regulating proteins involved in housekeeping, nitrogen metabolism, heat shock, iron transport, flagellar proteins, and several other cellular functions during stationary phase growth, $R$. conorii genome harbors only two conserved sigma factors, namely RpoD $\left(\sigma^{70}\right)$ and $\mathrm{RpoH}\left(\sigma^{32}\right)$ involved in regulating housekeeping and heat shock proteins, respectively. In addition, the existence of extracytoplasmic functional sigma factors (ECFs), small regulatory proteins exhibiting divergent sequences relative to known sigma factors, is well documented in many bacterial genomes and nearly 2700 ECFs from hundreds of bacterial genomes have been reported to date $[85,86]$. Upon receiving a stimulus, ECFs are synthesized and released, which then bind to $\mathrm{E}$ and regulate a wide array of genes involved in oxidative stress, resistance to high temperatures and antibiotics, starvation responses and other cellular functions. For instance, the ECF RpoE4 of Rhizobium etli is known to regulate 98 genes, a majority of which are involved in cell envelope biogenesis and stress responses [87]. Rickettsial genomes also encode for several hypothetical proteins and it is possible that some of these proteins might act as ECFs regulating transcriptional expression of genes involved in multiple pathways. Collectively, based on these reports and our findings in this study of the increased expression of $6 \mathrm{~S}$ RNA during infection of HMECs but not tick cells, differential expression of $R$. conorii genes depending on the host niche, and identification of a significantly greater number of genes to be transcribed during the infection of tick cells than in host HMECs, we propose a model (Fig. 6) implicating a role for 6S RNA in the regulation of $R$. conorii coding transcriptome during host-pathogen and vector-pathogen interactions. Based on our model, it is likely that increased accumulation of $6 \mathrm{~S}$ RNA at later stages (18-24h) of infection of the host cells results in the sequestration of $\mathrm{E \sigma}^{70}$, leading to the downregulation of housekeeping genes, thus allowing other sigma factors including ECFs to actively bind to RNA 


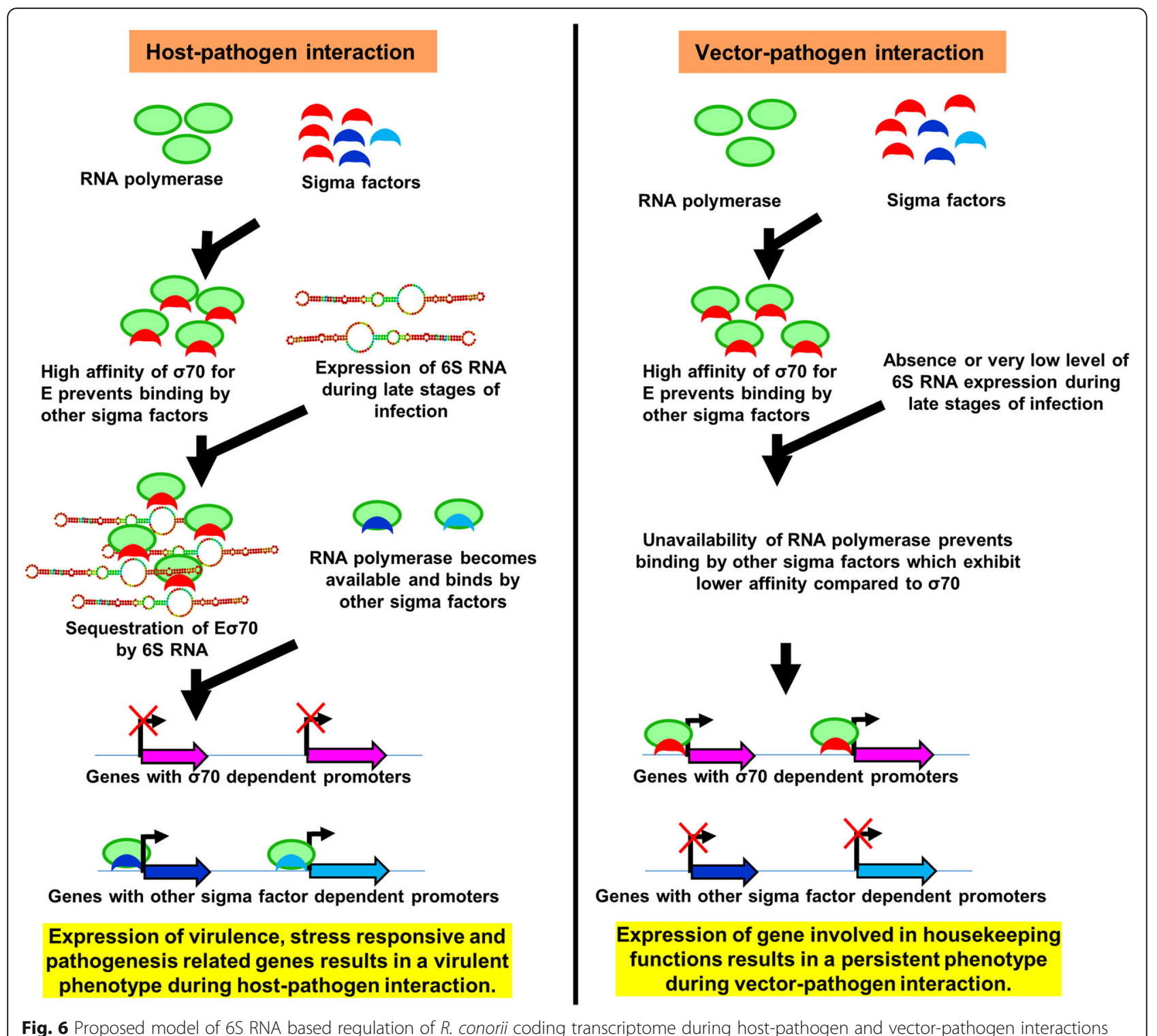

polymerase and regulate the expression of genes involved in functions such as oxidative stress response leading to virulence phenotype during host-pathogen interactions. In contrast, lower levels with no detectable changes in the expression profile of $6 \mathrm{~S}$ throughout the course of $R$. conorii infection of tick cells directly results in reduced sequestration and increased availability of $\mathrm{E \sigma}^{70}$, resulting in the transcription of more housekeeping genes and leading to a persistent phenotype during vector-pathogen interactions. Further ongoing investigations focused on characterizing the roles of $6 \mathrm{~S}$ RNA in rickettsial genomes will shed light on the regulatory mechanisms of this global transcriptional regulator during tripartite hostpathogen-vector interactions.

\section{Conclusions}

$R$. conorii is an arthropod vector-borne obligately intracellular pathogen, which survives in its arthropod host as part of the natural life-cycle, but causes human disease leading to vascular edema, infection of central nervous system and other organs, and mortality if not diagnosed and treated early. However, the mechanisms by which Rickettsia species regulate their transcriptome during persistence (vector-pathogen interaction) and pathogenesis (host-pathogen interaction) is not clearly understood. In this study, we decoded the coding and non-coding transcriptional landscape and identified transcription start sites of coding transcripts of $R$. conorii during in vitro infection of human host and tick vector cells. Our results suggest a greater number of $R$. conorii 
genes to be transcribed above the limit of detection during the infection of tick cells, of which 305 genes are differentially upregulated ( $>2$-fold) when compared to human host cells. In contrast, only $132 R$. conorii genes are upregulated at $>2$ fold in HMECs when compared to tick cells. Enrichment of primary transcripts by Terminator 5'Phosphate-dependent Exonuclease treatment enabled the identification of 3903 and 2555 TSSs in R. conorii during the infection to tick and human host cells, respectively. Most strikingly, we have further identified 32 novel $R c_{-}$ sRs, which are highly expressed in $R$. conorii during the infection of tick vector cells. Finally, 6S RNA was identified to be differentially expressed during host-pathogen and vector-pathogen interactions, implicating a role for this common bacterial noncoding RNA in the regulation of rickettsial transcriptome depending on the host niche.

\section{Methods}

\section{Cell culture}

Human microvascular endothelial cells (HMECs), an immortalized cell line of dermal origin, were obtained from the Centers for Disease Control, Atlanta, GA. HMECs were grown in MCDB131 medium supplemented with $10 \% \mathrm{v} / \mathrm{v}$ fetal bovine serum (FBS) (Aleken Biologicals), $10 \mathrm{ng} / \mathrm{mL}$ epidermal growth factor (Thermo Fisher Scientific), $10 \mathrm{mML}$-glutamine (Thermo Fisher Scientific), and $1 \mu \mathrm{g} / \mathrm{mL}$ hydrocortisone (Sigma) in a cell culture incubator maintained at $37^{\circ} \mathrm{C}$ and $5 \% \mathrm{CO}_{2}$. Cells from Amblyomma americanum ticks (AAE2) were kindly provided by Dr. Ulrike Munderloh (University of Minnesota, USA). The AAE2 cells were cultured in L15B complete medium supplemented with $20 \% \mathrm{v} / \mathrm{v}$ FBS (Harlan Bioproducts) and maintained at $34{ }^{\circ} \mathrm{C}$ as described previously [88]. The Vero E6 (African green monkey kidney fibroblasts) cells were cultured in Dulbecco's modified eagle medium (DMEM) supplemented with $2-10 \% \mathrm{v} / \mathrm{v} \mathrm{FBS}$ at $37^{\circ} \mathrm{C}$ in an atmosphere of $5 \%$ $\mathrm{CO}_{2}$ [89]. All cell lines were exempt by the University of Texas Medical Branch (UTMB) Institutional Review Board (IRB), and approved by the UTMB Institutional Biosafety Committee (IBC) for the use in these studies.

\section{Preparation and quantification of $\boldsymbol{R}$. conorii stocks}

Stocks of Rickettsia conorii were prepared in Vero E6 cells using established protocols and procedures [90]. $R$. conorii stocks prepared from the yolk-sacs of fertilized eggs as described earlier [91] were used for further propagation in Vero cells. Briefly, confluent Vero cell monolayers in DMEM containing 2\% FBS were infected with $R$. conorii and incubated at $35^{\circ} \mathrm{C}, 5 \% \mathrm{CO}_{2}$. The cultures were monitored microscopically at about $24 \mathrm{~h}$ intervals and $R$. conorii was harvested when approximately $30-40 \%$ of Vero cells detached from the culture surface. Rickettsiae were purified by differential centrifugation, enumerated by quantitative PCR using primers specific for rickettsial citrate synthase $(g l t A)$ gene and by plaque assay as described earlier, and stored as $\leq 500 \mu \mathrm{l}$ aliquots at $-80{ }^{\circ} \mathrm{C}$ until further use to prevent repeated freezing and thawing [24].

The growth of $R$. conorii in human and tick cells was determined by quantitative PCR as described earlier [24, 92]. Briefly, HMECs infected with $R$. conorii were maintained at $34{ }^{\circ} \mathrm{C}$ or $37^{\circ} \mathrm{C}$, while AAE2 cells were infected at $34{ }^{\circ} \mathrm{C}$ for the duration of the experiment. At $24 \mathrm{~h}$ post-infection, cell monolayer was washed twice with sterile PBS and incubated with DNase I $(10 \mathrm{U} / \mathrm{ml}$ for 30 min) to remove extracellular bacteria. At the end of incubation, monolayer was washed twice with sterile PBS and genomic DNA was extracted using a DNeasy blood and tissue kit (Qiagen) following the manufacturer's protocol. Absolute quantification of rickettsial load was performed by q-PCR using citrate synthase gene specific primers described previously $[92,93]$.

\section{Infection of HMECs and AAE2 cells with $R$. conorii and total RNA extraction}

Monolayers of HMECs at about 80 to $90 \%$ confluence were infected with $R$. conorii at an MOI of 50 following standard protocols. The MOI of 50 was chosen to increase the abundance of bacterial transcripts as eukaryotic transcripts, despite enrichment for microbial coding and non-coding RNAs, tend to interfere with library preparation and sequencing [23]. $R$. conorii infection was performed in a minimal volume of medium with gentle swirling of culture flasks for about $15 \mathrm{~min}$ to enhance the contact between bacteria and host cells, resulting in efficient adhesion and internalization of rickettsiae. At this point, additional culture medium was added to each flask to bring the total volume to about $3 \mathrm{ml}$ and cells were incubated at either $37^{\circ} \mathrm{C}$ or $34^{\circ} \mathrm{C}$ depending on the objective of the experiment for an additional 3 or $24 \mathrm{~h}$ as early and late time points of infection, respectively. For quantitative PCR, HMECs incubated with $R$. conorii for the first 15 min were used as a baseline control as described [24].

Infection of AAE 2 cells was performed in $25 \mathrm{~cm}^{2}$ flasks as described [24]. The L15B complete medium was replaced with the minimal volume of L15B infection medium prior to addition of $R$. conorii. The cells were infected with the inoculum of a pre-determined stock as described above, followed by gentle swirling and incubated for $15 \mathrm{~min}$ at $34^{\circ} \mathrm{C}$. Finally, $3 \mathrm{ml}$ of fresh L15B medium was added to each flask and the cells were further incubated for $3 \mathrm{~h}$ and $24 \mathrm{~h}$.

Total RNA isolation was carried out using Tri-Reagent (Molecular Research Center) following an optimized version of the manufacturer's protocol. At each time point, culture medium was aspirated off carefully and the cells (HMECs or AAE2) infected with $R$. conorii were lysed in 
Tri-Reagent and processed for RNA isolation using our standard laboratory protocol. Total RNA thus obtained was subjected to DNase I treatment to eliminate genomic DNA contamination, purified by precipitation with $3 \mathrm{M}$ sodium acetate $\mathrm{pH} 5.5$ (Ambion) and glycogen $(5 \mu \mathrm{g} / \mathrm{mL})$ (Ambion), and dissolved in nuclease-free water. The quality of total RNA preparations was assessed on a Bioanalyzer (Agilent Technologies) and only samples with an RNA integrity number (RIN) score of $\geq 9.0$ were used for sequencing.

\section{Library preparation and data analysis}

RNA samples were enriched for bacterial coding and noncoding transcripts using Dynabeads Oligo $(\mathrm{dT})_{25}$ (Thermo Fisher Scientific) and Ribo-Zero Gold rRNA Removal Kit (Epidemiology) (Illumina) to remove mRNAs (eukaryotic) and rRNAs (bacterial, eukaryotic, and mitochondrial), respectively. Enriched RNA from each biological replicate was then split into two equal aliquots, of which one was treated with Terminator 5'-Phosphate-dependent Exonuclease (TEX) to remove processed transcripts and designated as '+TEX'. The other untreated aliquot containing both primary (5'-triphosphate) and processed (5'-monophosphate) transcripts was designated as '-TEX'. Complementary DNA libraries for each sample were prepared independently using TruSeq RNA Sample Prep Kit following manufacturer instructions (Illumina). Strand-specific, paired end reads of 100 bases in length were sequenced on an Illumina HiSeq 1500 at the institutional Next Generation Sequencing core facility of the UTMB. A minimum of 70 million reads were sequenced from each biological replicate. The sequences were analyzed using the CLC Genomics Workbench 12.0.3 Microbial Genomics Module. Reads containing nucleotides below the quality threshold of 0.05 (using the modified Richard Mott algorithm) and those with two or more unknown nucleotides or sequencing adapters were trimmed out. The reads from each library were mapped to $R$. conorii genome (NC_003103.1) in PATRIC database in light of its consistency for the annotation of rickettsial genomes. The criteria for read mapping included an allowance of up to two mismatches per read and removal of all unmapped reads from the analysis [24]. Reads per kilobase per million of mapped reads (RKPM) were calculated using the formula: Total reads mapping to the gene (ORF) / [mapped reads (million) * gene length (kb)]. To avoid an intrinsic statistical bias, we calculated transcripts per million (TPM) for each expressed transcript (ORF) as described previously [25] using the formula: RKPM *10 / RKPM.

\section{Quantitative RT-PCR}

To confirm the expression profile of novel $R c \_s R s$ and differentially expressed genes, we performed quantitative RT-PCR of three sRNAs (Rc_sR61, sR71, and sR74) and two rickettsial transcripts (RC0149 and RC0511) during in vitro infection of human ECs and tick cells. One microgram of total RNA was reverse transcribed using random primers and high capacity reverse transcription kit (Invitrogen) according to the manufacturer's protocol. SYBR green based RT-qPCR was performed using sRNA- or gene-specific primer pairs and rickettsial $16 \mathrm{~S}$ RNA as an endogenous control to account for and nullify the differences in bacterial load between samples. The expression profile of $R$. conorii 6S RNA was assessed by a TaqMan assay described previously [22]. Total RNA was reverse transcribed as described above and custom synthesized 6S RNA primers and probe as well as the corresponding 16S RNA primers and probe were used to quantify transcript abundance at different times during the course of infection. Owing to the obligate intracellular lifestyle of rickettsiae, cells infected for only $15 \mathrm{~min}$ served as the baseline control and relative quantity was calculated as described below. The ${ }^{\Delta} \mathrm{Ct}$ values for $R$. conorii-infected cells at $3 \mathrm{~h}$ and $24 \mathrm{~h}$ were compared to those infected for $15 \mathrm{~min}$ (designated as the baseline control), which was assigned a value of 1 . Relative expression was determined by comparative $\mathrm{Ct}$ $\left({ }^{-\Delta \Delta} \mathrm{Ct}\right.$ method) [94]. Briefly, expression of $R$. conorii genes or sRNAs was quantified using specific primers and rickettsial $16 \mathrm{~S}$ rRNA as the housekeeping control. To obtain ${ }^{\Delta} \mathrm{Ct}$ values, the $\mathrm{Ct}$ values for target gene and sRNA at each time point were normalized to the $\mathrm{Ct}$ value for 16S RNA using the StepOne ${ }^{\text {TM }}$ Plus software version 2.3. We determined relative expression of target sRNA or genes at $3 \mathrm{~h}$ and $24 \mathrm{~h}$ by comparing normalized target quantity at each time point to the normalized quantity in cells infected for $15 \mathrm{~min}$ (baseline control). The data thus obtained were plotted as the fold-change over basal expression [94]. The values from a minimum of three independent biological replicates processed as two technical replicates for each time point were analyzed by ${ }^{-\Delta \Delta} \mathrm{Ct}$ method. All primers and probes used in this study are listed in Additional file 8.

\section{Identification of transcription start sites (TSSs)}

Quality trimmed reads from +TEX and -TEX libraries mapping to $R$. conorii genome were used for the identification of TSSs using the program TSSAR (http://rna.tbi. univie.ac.at/TSSAR/) with default parameters [95]. The TSSs were classified as primary (within 250 nucleotides upstream of the gene translational start site), internal (within the coding gene), antisense (on the opposite strand of an annotated gene), or orphan (anywhere else including the intergenic region of the genome), depending on their genomic location with respect to the gene annotation. The antisense TSSs were further subdivided as 'AiTSS' (TSS on the opposite strand and within the coding ORF) and 'AdTSS' (TSS on the anti-sense strand 
and within $30 \mathrm{bp}$ downstream of a stop codon of an annotated gene) depending on their genomic location.

\section{Statistical analysis}

All quantitative RT-PCR experiments were performed on a minimum of three independent biological replicates with two technical replicates for each time point. The data was analyzed using GraphPad Prism and calculated as the mean \pm standard error of the mean (SEM). Statistical analysis was performed using Mann-Whitney t-test with a significance threshold of $p \leq 0.05$.

\section{Supplementary information}

Supplementary information accompanies this paper at https://doi.org/10. 1186/s12864-020-07077-w

Additional file 1 Growth kinetics of $R$. conorii in HMECs infected and maintained at either $34^{\circ} \mathrm{C}$ or $37^{\circ} \mathrm{C}$, and AAE2 cells infected and maintained at $34^{\circ} \mathrm{C}$, for $24 \mathrm{~h}$ post-infection.

Additional file 2 List of $R$. conorii coding genes and their expression during infection of HMECs and AAE2 cells, in vitro.

Additional file 3 Expression of genes involved in LPS biosynthesis and transport (A), type IV secretion system and known rickettsial effectors (B), and genes encoding ankyrin repeat proteins (C) in R. conorii during infection of HMECs and AAE2 cells, in vitro.

Additional file 4 List of different categories ( $\mathrm{Ad}, \mathrm{Ai}, \mathrm{I}, \mathrm{O}$ and IP) of transcription start sites identified by TSSAR in R. conorii genome during the infection of HMECs, in vitro.

Additional file $\mathbf{5}$ List of different categories ( $\mathrm{Ad}, \mathrm{Ai}, \mathrm{I}, \mathrm{O}$ and IP) of transcription start sites identified by TSSAR in $R$. conorii genome during the infection of AAE2 cells, in vitro.

Additional file $\mathbf{6}$ List of primary transcription start sites (pTSS) identified for $R$. conorii transcripts expressed during the infection of tick vector $(\mathrm{AAE} 2+R c)$ and human host $(\mathrm{HMEC}+R \mathrm{C})$ cells, in vitro.

Additional file $\mathbf{7}$ List of small RNAs identified in $R$. conorii genome.

Additional file 8. List of primers used in this study.

\section{Abbreviations}

EC's: Endothelial cells; ECFs: Extracytoplasmic functional sigma factors; HMECs: Human microvascular endothelial cells; MOl: Multiplicity of infection; mRNA: Messenger ribonucleic acid; TSS: Transcription start site; Re_sR's: Rickettsia conorii small RNA; RT-PCR: Reverse transcriptase polymerase chain reaction; RKPM: Reads per kilobase million; sRNA: Small ribonucleic acid; TEX: Terminator 5'-Phosphate-dependent Exonuclease; TPM: Transcripts per million

\section{Acknowledgements}

We thank Dr. Steve Widen and Jill Thompson for providing support with the library preparation and sequencing of samples at the Next Generation Sequencing core facility of the UTMB.

\section{Authors' contributions}

HPN conceptualized the study, designed and performed all in vitro experiments, analyzed the data and prepared the first draft of the manuscript; AS assisted with preparation of rickettsial stocks, in vitro experiments and cell culture; JA helped with analysis and in vitro experiments; CLCS helped with data analysis and quantification of rickettsial stock required for tick cell infections; KK, GG, AN and YF provided bioinformatics support for data analysis, calculation of RKPM and TPM values, and identification of transcription start sites in $R$. conorii genome; SKS conceived the study, participated in design, coordination, data analysis and assisted with finalizing the manuscript. All authors read and approved the final manuscript.

\section{Funding}

This study was supported in part by research project grants 5 R01 Al12789903 and 1 R21 Al144888-01A1 from the National Institute of Allergy and Infectious Diseases at the National Institutes of Health, Bethesda, MD, USA, and pilot funding from the Institute for Human Infections and Immunity at the University of Texas Medical Branch, Galveston, TX, USA.

\section{Availability of data and materials}

The data from this study are included in this published article and its supplementary additional files. The raw sequencing data is deposited to the NCBI database under accession number PRJNA657619.

\section{Ethics approval and consent to participate}

Not applicable.

\section{Competing interests}

The authors declare that they have no competing interests.

\section{Author details}

'Department of Pathology, University of Texas Medical Branch, Galveston, TX 77555 , USA. ${ }^{2}$ Department of Pharmacology and Toxicology, University of Texas Medical Branch, Galveston, TX 77555, USA. ${ }^{3}$ Biochemistry and Molecular Biology, University of Texas Medical Branch, Galveston, TX 77555, USA.

Received: 28 April 2020 Accepted: 17 September 2020

Published online: 25 September 2020

References

1. Azad AF. Pathogenic rickettsiae as bioterrorism agents. Clin Infect Dis. 2007; 45(Suppl 1):S52-5.

2. Sahni A, Fang R, Sahni SK, Walker DH. Pathogenesis of rickettsial diseases: pathogenic and immune mechanisms of an endotheliotropic infection. Annu Rev Pathol. 2018.

3. Parola P, Paddock CD, Socolovschi C, Labruna MB, Mediannikov O, Kernif $T$, et al. Update on tick-borne rickettsioses around the world: a geographic approach. Clin Microbiol Rev. 2013:26:657-702.

4. Sahni SK, Narra HP, Sahni A, Walker DH. Recent molecular insights into rickettsial pathogenesis and immunity. Future Microbiol. 2013;8:1265-88.

5. Ellison DW, Clark TR, Sturdevant DE, Virtaneva K, Hackstadt T. Limited transcriptional responses of Rickettsia rickettsii exposed to environmental stimuli. PLoS One. 2009:4:e5612.

6. Dreher-Lesnick SM, Ceraul SM, Rahman MS, Azad AF. Genome-wide screen for temperature-regulated genes of the obligate intracellular bacterium, Rickettsia typhi. BMC Microbiol. 2008;8:61.

7. Galletti MF, Fujita A, Nishiyama MY Jr, Malossi CD, Pinter A, Soares JF, et al. Natural blood feeding and temperature shift modulate the global transcriptional profile of Rickettsia rickettsii infecting its tick vector. PLoS One. 2013;8:e77388

8. Galletti MF, Fujita A, Rosa RD, Martins LA, Soares HS, Labruna MB, et al. Virulence genes of Rickettsia rickettsii are differentially modulated by either temperature upshift or blood-feeding in tick midgut and salivary glands. Parasit Vectors. 2016:9:331

9. Nelson CM, Herron MJ, Wang XR, Baldridge GD, Oliver JD, Munderloh UG. Global transcription profiles of Anaplasma phagocytophilum at key stages of infection in tick and human cell lines and granulocytes. Front Vet Sci. 2020; 7:111.

10. Kuriakose JA, Miyashiro S, Luo T, Zhu B, McBride JW. Ehrlichia chaffeensis transcriptome in mammalian and arthropod hosts reveals differential gene expression and post transcriptional regulation. PLoS One. 2011;6:e24136

11. de Silva AM, Fikrig E. Arthropod- and host-specific gene expression by Borrelia burgdorferi. J Clin Invest. 1997;99:377-9.

12. Nelson CM, Herron MJ, Felsheim RF, Schloeder BR, Grindle SM, Chavez AO, et al. Whole genome transcription profiling of Anaplasma phagocytophilum in human and tick host cells by tiling array analysis. BMC Genomics. 2008;9:364

13. Tilly K, Bestor A, Rosa PA. Functional equivalence of OspA and OspB, but not OspC, in tick colonization by Borrelia burgdorferi. Infect Immun. 2016;84: 1565-73.

14. Gilmore RD Jr, Piesman J. Inhibition of Borrelia burgdorferi migration from the midgut to the salivary glands following feeding by ticks on OspCimmunized mice. Infect Immun. 2000;68:411-4. 
15. Neelakanta G, Li X, Pal U, Liu X, Beck DS, DePonte K, et al. Outer surface protein $B$ is critical for Borrelia burgdorferi adherence and survival within Ixodes ticks. PLoS Pathog. 2007;3:e33.

16. Hellwage J, Meri T, Heikkila T, Alitalo A, Panelius J, Lahdenne P, et al. The complement regulator factor $\mathrm{H}$ binds to the surface protein OspE of Borrelia burgdorferi. J Biol Chem. 2001;276:8427-35.

17. Pal U, Fikrig E. Adaptation of Borrelia burgdorferi in the vector and vertebrate host. Microbes Infect. 2003;5:659-66.

18. Popitsch N, Bilusic I, Rescheneder P, Schroeder R, Lybecker M. Temperaturedependent sRNA transcriptome of the Lyme disease spirochete. BMC Genomics. 2017;18:28

19. Cheah HL, Raabe CA, Lee LP, Rozhdestvensky TS, Citartan M, Ahmed SA, et al. Bacterial regulatory RNAs: complexity, function, and putative drug targeting. Crit Rev Biochem Mol Biol. 2018;53:335-55.

20. Bojanovic K, D'Arrigo I, Long KS. Global transcriptional responses to osmotic, oxidative, and imipenem stress conditions in Pseudomonas putida. Appl Environ Microbiol. 2017;83.

21. Westermann AJ, Forstner KU, Amman F, Barquist L, Chao Y, Schulte LN, et al. Dual RNA-seq unveils noncoding RNA functions in host-pathogen interactions. Nature. 2016;529:496-501.

22. Schroeder CL, Narra HP, Rojas M, Sahni A, Patel J, Khanipov K, et al. Bacterial small RNAs in the genus Rickettsia. BMC Genomics. 2015;16:1075.

23. Schroeder CL, Narra HP, Sahni A, Rojas M, Khanipov K, Patel J, et al. Identification and characterization of novel small RNAs in Rickettsia prowazekii. Front Microbiol. 2016;7:859.

24. Narra HP, Schroeder CL, Sahni A, Rojas M, Khanipov K, Fofanov Y, et al. Small regulatory RNAs of Rickettsia conorii. Sci Rep. 2016;6:36728.

25. Schroeder CLC, Narra HP, Sahni A, Khanipov K, Patel J, Fofanov Y, et al. Transcriptional profiling of Rickettsia prowazekii coding and non-coding transcripts during in vitro host-pathogen and vector-pathogen interactions. Ticks Tick Borne Dis. 2017:8:827-36.

26. Kumar N, Lin M, Zhao X, Ott S, Santana-Cruz I, Daugherty S, et al. Efficient enrichment of bacterial mRNA from host-bacteria total RNA samples. Sci Rep. 2016;6:34850.

27. Niebylski ML, Peacock MG, Schwan TG. Lethal effect of Rickettsia rickettsii on its tick vector (Dermacentor andersoni). Appl Environ Microbiol. 1999;65:773-8.

28. Patel JG, Narra HP, Sepuru KM, Sahni A, Golla SR, Sahni A, et al. Evolution, purification, and characterization of RC0497: a peptidoglycan amidase from the prototypical spotted fever species Rickettsia conorii. Biol Chem. 2020;401:249-62.

29. Zhao Y, Fang R, Zhang J, Zhang Y, Bechelli J, Smalley C, et al. Quantitative proteomics of the endothelial secretome identifies RC0497 as diagnostic of acute rickettsial spotted fever infections. Am J Pathol. 2020;190:306-22.

30. Audia JP, Patton MC, Winkler HH. DNA microarray analysis of the heat shock transcriptome of the obligate intracytoplasmic pathogen Rickettsia prowazekii. Appl Environ Microbiol. 2008;74:7809-12.

31. Ogawa M, Renesto P, Azza S, Moinier D, Fourquet P, Gorvel JP, et al. Proteome analysis of Rickettsia felis highlights the expression profile of intracellular bacteria. Proteomics. 2007;7:1232-48.

32. Moran NA. Accelerated evolution and Muller's rachet in endosymbiotic bacteria. Proc Natl Acad Sci U S A. 1996:93:2873-8.

33. Fares MA, Moya A, Barrio E. Adaptive evolution in GroEL from distantly related endosymbiotic bacteria of insects. J Evol Biol. 2005;18:651-60.

34. Sabater-Munoz B, Prats-Escriche M, Montagud-Martinez R, Lopez-Cerdan A, Toft C, Aguilar-Rodriguez J, et al. Fitness trade-offs determine the role of the molecular chaperonin GroEL in buffering mutations. Mol Biol Evol. 2015;32:2681-93.

35. Yamanaka K, Fang L, Inouye M. The CspA family in Escherichia coli: multiple gene duplication for stress adaptation. Mol Microbiol. 1998;27:247-55.

36. Schmid B, Klumpp J, Raimann E, Loessner MJ, Stephan R, Tasara T. Role of cold shock proteins in growth of listeria monocytogenes under cold and osmotic stress conditions. Appl Environ Microbiol. 2009;75:1621-7.

37. Caballero CJ, Menendez-Gil P, Catalan-Moreno A, Vergara-Irigaray M, Garcia $B$, Segura $V$, et al. The regulon of the RNA chaperone CspA and its autoregulation in Staphylococcus aureus. Nucleic Acids Res. 2018;46:1345-61.

38. Loepfe C, Raimann E, Stephan R, Tasara T. Reduced host cell invasiveness and oxidative stress tolerance in double and triple csp gene family deletion mutants of Listeria monocytogenes. Foodborne Pathog Dis. 2010;7:775-83.

39. Wang Z, Liu W, Wu T, Bie P, Wu Q. RNA-seq reveals the critical role of CspA in regulating Brucella melitensis metabolism and virulence. Sci China Life Sci. 2016;59:417-24.

40. Wang Z, Wang S, Wu Q. Cold shock protein a plays an important role in the stress adaptation and virulence of Brucella melitensis. FEMS Microbiol Lett 2014;354:27-36
41. Lamason RL, Welch MD. Actin-based motility and cell-to-cell spread of bacterial pathogens. Curr Opin Microbiol. 2017;35:48-57.

42. Harris EK, Jirakanwisal K, Verhoeve VI, Fongsaran C, Suwanbongkot C, Welch MD, et al. Role of Sca2 and RickA in the dissemination of Rickettsia parkeri in Amblyomma maculatum. Infect Immun. 2018;86.

43. Audoly G, Vincentelli R, Edouard S, Georgiades K, Mediannikov O, Gimenez $\mathrm{G}$, et al. Effect of rickettsial toxin VapC on its eukaryotic host. PLoS One. 2011;6:e26528.

44. Botelho-Nevers E, Edouard S, Leroy Q, Raoult D. Deleterious effect of ciprofloxacin on Rickettsia conorii-infected cells is linked to toxin-antitoxin module up-regulation. J Antimicrob Chemother. 2012;67:1677-82.

45. Keren I, Shah D, Spoering A, Kaldalu N, Lewis K. Specialized persister cells and the mechanism of multidrug tolerance in Escherichia coli. J Bacteriol. 2004; 186:8172-80.

46. Wang X, Wood TK. Toxin-antitoxin systems influence biofilm and persister cell formation and the general stress response. Appl Environ Microbiol. 2011;77:5577-83.

47. Kaur SJ, Rahman MS, Ammerman NC, Beier-Sexton M, Ceraul SM, Gillespie $\mathrm{JJ}$, et al. TolC-dependent secretion of an ankyrin repeat-containing protein of Rickettsia typhi. J Bacteriol. 2012;194:4920-32.

48. Lehman SS, Noriea NF, Aistleitner K, Clark TR, Dooley CA, Nair V, et al. The rickettsial ankyrin repeat protein 2 is a type IV secreted effector that associates with the endoplasmic reticulum. MBio. 2018;9.

49. Aistleitner K, Clark T, Dooley C, Hackstadt T. Selective fragmentation of the trans-Golgi apparatus by Rickettsia rickettsii. PLoS Pathog. 2020;16:e1008582.

50. VieBrock L, Evans SM, Beyer AR, Larson CL, Beare PA, Ge H, et al. Orientia tsutsugamushi ankyrin repeat-containing protein family members are type 1 secretion system substrates that traffic to the host cell endoplasmic reticulum. Front Cell Infect Microbiol. 2014:4:186.

51. Evans SM, Rodino KG, Adcox HE, Carlyon JA. Orientia tsutsugamushi uses two Ank effectors to modulate NF-kappaB p65 nuclear transport and inhibit NF-kappaB transcriptional activation. PLoS Pathog. 2018;14:e1007023.

52. Beyer AR, VieBrock L, Rodino KG, Miller DP, Tegels BK, Marconi RT, et al. Orientia tsutsugamushi strain Ikeda ankyrin repeat-containing proteins recruit SCF1 ubiquitin ligase machinery via poxvirus-like F-box motifs. J Bacteriol. 2015;197:3097-109.

53. Hase CC, Finkelstein RA. Bacterial extracellular zinc-containing metalloproteases. Microbiol Rev. 1993;57:823-37.

54. Bozhokina E, Kever L, Khaitlina S. The Serratia grimesii outer membrane vesicles-associated grimelysin triggers bacterial invasion of eukaryotic cells. Cell Biol Int. 2020.

55. Valeri M, Rossi Paccani S, Kasendra M, Nesta B, Serino L, Pizza M, et al. Pathogenic E coli exploits SsIE mucinase activity to translocate through the mucosal barrier and get access to host cells. PLoS One. 2015;10:e0117486.

56. Cerveny L, Straskova A, Dankova V, Hartlova A, Ceckova M, Staud F, et al. Tetratricopeptide repeat motifs in the world of bacterial pathogens: role in virulence mechanisms. Infect Immun. 2013;81:629-35.

57. Walburger A, Koul A, Ferrari G, Nguyen L, Prescianotto-Baschong C, Huygen $\mathrm{K}$, et al. Protein kinase $\mathrm{G}$ from pathogenic mycobacteria promotes survival within macrophages. Science. 2004;304:1800-4.

58. Allmond LR, Karaca TJ, Nguyen VN, Nguyen T, Wiener-Kronish JP, Sawa T. Protein binding between PcrG-PcrV and PcrH-PopB/PopD encoded by the pcrGVH-popBD operon of the Pseudomonas aeruginosa type III secretion system. Infect Immun. 2003;71:2230-3.

59. Mohapatra NP, Soni S, Rajaram MV, Dang PM, Reilly TJ, El-Benna J, et al. Francisella acid phosphatases inactivate the NADPH oxidase in human phagocytes. J Immunol. 2010;184:5141-50.

60. Wurtzel O, Sapra R, Chen F, Zhu Y, Simmons BA, Sorek R. A single-base resolution map of an archaeal transcriptome. Genome Res. 2010;20:133-41.

61. Wade JT, Grainger DC. Pervasive transcription: illuminating the dark matter of bacterial transcriptomes. Nat Rev Microbiol. 2014;12:647-53.

62. He Y, Vogelstein B, Velculescu VE, Papadopoulos N, Kinzler KW. The antisense transcriptomes of human cells. Science. 2008;322:1855-7.

63. Thomason MK, Bischler T, Eisenbart SK, Forstner KU, Zhang A, Herbig A, et al. Global transcriptional start site mapping using differential RNA sequencing reveals novel antisense RNAs in Escherichia coli. J Bacteriol. 2015;197:18-28.

64. Zhukova A, Fernandes LG, Hugon P, Pappas CJ, Sismeiro O, Coppee JY, et al Genome-wide transcriptional start site mapping and sRNA identification in the pathogen Leptospira interrogans. Front Cell Infect Microbiol. 2017;7:10.

65. Adams PP. Flores Avile C, Popitsch N, Bilusic I, Schroeder R, Lybecker M, et al. In vivo expression technology and $5^{\prime}$ end mapping of the Borrelia 
burgdorferi transcriptome identify novel RNAs expressed during mammalian infection. Nucleic Acids Res. 2017;45:775-92.

66. Sharma CM, Hoffmann S, Darfeuille F, Reignier J, Findeiss S, Sittka A, et al. The primary transcriptome of the major human pathogen Helicobacter pylori. Nature. 2010;464:250-5.

67. Raghavan $\mathrm{R}$, Sloan $\mathrm{DB}$, Ochman $\mathrm{H}$. Antisense transcription is pervasive but rarely conserved in enteric bacteria. MBio. 2012;3.

68. Chatterjee A, Johnson CM, Shu CC, Kaznessis YN, Ramkrishna D, Dunny GM, et al. Convergent transcription confers a bistable switch in Enterococcus faecalis conjugation. Proc Natl Acad Sci U S A. 2011;108:9721-6.

69. Lee EJ, Groisman EA. An antisense RNA that governs the expression kinetics of a multifunctional virulence gene. Mol Microbiol. 2010;76:1020-33.

70. Chakravarty S, Masse E. RNA-dependent regulation of virulence in pathogenic bacteria. Front Cell Infect Microbiol. 2019;9:337.

71. Saberi F, Kamali M, Najafi A, Yazdanparast A, Moghaddam MM. Natural antisense RNAs as mRNA regulatory elements in bacteria: a review on function and applications. Cell Mol Biol Lett. 2016:21:6.

72. Wagner EG. Kill the messenger: bacterial antisense RNA promotes mRNA decay. Nat Struct Mol Biol. 2009;16:804-6.

73. Yang Z, Jin X, Rao X, Hu F. A natural antisense transcript regulates mucD gene expression and biofilm biosynthesis in Pseudomonas aeruginosa. Mikrobiologiia. 2011;80:756-62.

74. Brophy JA, Voigt CA. Antisense transcription as a tool to tune gene expression. Mol Syst Biol. 2016;12:854.

75. Cai J, Pang H, Wood DO, Winkler HH. The citrate synthase-encoding gene of Rickettsia prowazekii is controlled by two promoters. Gene. 1995;163:115-9.

76. Thairu MW, Hansen AK. Changes in aphid host plant diet influence the small-RNA expression profiles of its obligate nutritional symbiont, Buchnera. mBio. 2019;10.

77. Thairu MW, Cheng S, Hansen AK. A sRNA in a reduced mutualistic symbiont genome regulates its own gene expression. Mol Ecol. 2018;27:1766-76.

78. Rau MH, Bojanovic K, Nielsen AT, Long KS. Differential expression of small RNAs under chemical stress and fed-batch fermentation in E coli. BMC Genomics. 2015;16:1051

79. Wassarman KM. 65 RNA, a global regulator of transcription. Microbiol Spectr. 2018;6.

80. Warrier I, Hicks LD, Battisti JM, Raghavan R, Minnick MF. Identification of novel small RNAs and characterization of the 6S RNA of Coxiella burnetii. PLoS One. 2014;9:e100147.

81. Darby AC, Armstrong SD, Bah GS, Kaur G, Hughes MA, Kay SM, et al. Analysis of gene expression from the Wolbachia genome of a filarial nematode supports both metabolic and defensive roles within the symbiosis. Genome Res. 2012;22:2467-77.

82. Drecktrah D, Hall LS, Brinkworth AJ, Comstock JR, Wassarman KM, Samuels DS. Characterization of 6S RNA in the Lyme disease spirochete. Mol Microbiol. 2020;113:399-417.

83. Trotochaud AE, Wassarman KM. 6S RNA function enhances long-term cell survival. J Bacteriol. 2004;186:4978-85.

84. Sharma UK, Chatterij D. Transcriptional switching in Escherichia coli during stress and starvation by modulation of sigma activity. FEMS Microbiol Rev. 2010;34:646-57.

85. Chevalier S, Bouffartigues E, Bazire A, Tahrioui A, Duchesne R, Tortuel D, et al. Extracytoplasmic function sigma factors in Pseudomonas aeruginosa. Biochim Biophys Acta Gene Regul Mech. 1862;2019:706-21.

86. Helmann JD. The extracytoplasmic function (ECF) sigma factors. Adv Microb Physiol. 2002;46:47-110.

87. Martinez-Salazar JM, Salazar E, Encarnacion S, Ramirez-Romero MA, Rivera J. Role of the extracytoplasmic function sigma factor RpoE4 in oxidative and osmotic stress responses in Rhizobium etli. J Bacteriol. 2009;191:4122-32.

88. Munderloh UG, Kurtti TJ. Formulation of medium for tick cell culture. Exp Appl Acarol. 1989;7:219-29.

89. Narra HP, Sahni A, Khanipov K, Fofanov Y, Sahni SK. Global transcriptomic profiling of pulmonary gene expression in an experimental murine model of Rickettsia conorii infection. Genes (Basel). 2019:10.

90. Ammerman NC, Beier-Sexton M, Azad AF. Laboratory maintenance of Rickettsia rickettsii. Curr Protoc Microbiol. 2008;Chapter 3:Unit 3A 5.

91. Alhassan A, Liu H, McGill J, Cerezo A, Jakkula L, Nair ADS, et al. Rickettsia rickettsii whole-cell antigens offer protection against rocky mountain spotted fever in the canine host. Infect Immun. 2019;87.

92. Labruna MB, Whitworth T, Horta MC, Bouyer DH, McBride JW, Pinter A, et al. Rickettsia species infecting Amblyomma cooperi ticks from an area in the state of Sao Paulo, Brazil, where Brazilian spotted fever is endemic. J Clin Microbiol. 2004;42:90-8.

93. Sahni A, Patel J, Narra HP, Schroeder CLC, Walker DH, Sahni SK. Fibroblast growth factor receptor-1 mediates internalization of pathogenic spotted fever rickettsiae into host endothelium. PLoS One. 2017;12:e0183181.

94. Schmittgen TD, Livak KJ. Analyzing real-time PCR data by the comparative C(T) method. Nat Protoc. 2008;3:1101-8.

95. Amman F, Wolfinger MT, Lorenz R, Hofacker IL, Stadler PF, Findeiss S. TSSAR: TSS annotation regime for dRNA-seq data. BMC Bioinformatics. 2014;15:89.

\section{Publisher's Note}

Springer Nature remains neutral with regard to jurisdictional claims in published maps and institutional affiliations.
Ready to submit your research? Choose BMC and benefit from:

- fast, convenient online submission

- thorough peer review by experienced researchers in your field

- rapid publication on acceptance

- support for research data, including large and complex data types

- gold Open Access which fosters wider collaboration and increased citations

- maximum visibility for your research: over $100 \mathrm{M}$ website views per year

At BMC, research is always in progress.

Learn more biomedcentral.com/submissions 